\title{
Complexin Mutants Reveal Partial Segregation between Recycling Pathways That Drive Evoked and Spontaneous Neurotransmission
}

\author{
Nadezhda Sabeva, ${ }^{3}$ - Richard W. Cho, ${ }^{4}{ }^{\circledR}$ Alexander Vasin, ${ }^{1}$ Agustin Gonzalez, ${ }^{3}{ }^{-0}$ J. Troy Littleton, ${ }^{4}$ \\ and Maria Bykhovskaia ${ }^{1,2,3}$ \\ ${ }^{1}$ Department of Neurology and 2Department of Anatomy and Cell Biology, Wayne State University School of Medicine, Detroit, Michigan 48201, \\ ${ }^{3}$ Neuroscience Department, Universidad Central del Caribe, Bayamon, Puerto Rico 00960, and ${ }^{4}$ Picower Institute for Learning and Memory, Department of \\ Biology, Department of Brain and Cognitive Sciences, Massachusetts Institute of Technology, Cambridge, Massachusetts 02139
}

\begin{abstract}
Synaptic vesicles fuse at morphological specializations in the presynaptic terminal termed active zones (AZs). Vesicle fusion can occur spontaneously or in response to an action potential. Following fusion, vesicles are retrieved and recycled within nerve terminals. It is still unclear whether vesicles that fuse spontaneously or following evoked release share similar recycling mechanisms. Genetic deletion of the SNARE-binding protein complexin dramatically increases spontaneous fusion, with the protein serving as the synaptic vesicle fusion clamp at Drosophila synapses. We examined synaptic vesicle recycling pathways at complexin null neuromuscular junctions, where spontaneous release is dramatically enhanced. We combined loading of the lipophilic dye FM1-43 with photoconversion, electron microscopy, and electrophysiology to monitor evoked and spontaneous recycling vesicle pools. We found that the total number of recycling vesicles was equal to those retrieved through spontaneous and evoked pools, suggesting that retrieval following fusion is partially segregated for spontaneous and evoked release. In addition, the kinetics of FM1-43 destaining and synaptic depression measured in the presence of the vesicle-refilling blocker bafilomycin indicated that spontaneous and evoked recycling pools partially intermix during the release process. Finally, FM1- 43 photoconversion combined with electron microscopy analysis indicated that spontaneous recycling preferentially involves synaptic vesicles in the vicinity of AZs, whereas vesicles recycled following evoked release involve a larger intraterminal pool. Together, these results suggest that spontaneous and evoked vesicles use separable recycling pathways and then partially intermix during subsequent rounds of fusion.
\end{abstract}

Key words: Drosophila; electron microscopy; endocytosis; exocytosis; FM1-43; synaptic

\section{Significance Statement}

Neurotransmitter release involves fusion of synaptic vesicles with the plasma membrane in response to an action potential, or spontaneously in the absence of stimulation. Upon fusion, vesicles are retrieved and recycled, and it is unclear whether recycling pathways for evoked and spontaneous vesicles are segregated after fusion. We addressed this question by taking advantage of preparations lacking the synaptic protein complexin, which have elevated spontaneous release that enables reliable tracking of the spontaneous recycling pool. Our results suggest that spontaneous and evoked recycling pathways are segregated during the retrieval process but can partially intermix during stimulation.

\section{Introduction}

Neurotransmitters are released by the exocytosis of synaptic vesicles with the neuronal plasma membrane. Vesicles are docked

Received June 9, 2016; revised Nov. 10, 2016; accepted Nov. 15, 2016.

Author contributions: J.T.L. and M.B. designed research; N.S., R.W.C., A.V., and A.G. performed research; N.S., R.W.C., A.V., and M.B. analyzed data; N.S., R.W.C., J.T.L., and M.B. wrote the paper.

This work was supported by National Institutes of Health Grant R01 MH099557 to M.B. and J.T.L.

The authors declare no competing financial interests.

Correspondence should be addressed to Dr. Maria Bykhovskaia, Neurology Department, 550 E. Canfield Drive,

Lande BIdg \#108, Detroit, MI 48202. E-mail: mbykhovs@med.wayne.edu. and released at morphological specializations termed active zones (AZs), which can be visualized with electron microscopy (EM) as filaments attached to the membrane and surrounded by vesicle clusters (Zhai and Bellen, 2004; Südhof, 2013b; Imig et al., 2014). Stimulus-evoked fusion occurs in response to $\mathrm{Ca}^{2+}$ influx into synaptic terminals following an action potential. Vesicles can also fuse and release transmitters spontaneously in the absence of 
stimuli, and this release mode is important for neuronal development and plasticity (Cho et al., 2010, 2014; Kavalali, 2015; Reese and Kavalali, 2015).

Following fusion, synaptic vesicles are retrieved into nerve terminals by endocytosis and recycled for additional rounds of fusion. Several endocytic pathways have been described, including clathrin-mediated endocytosis at periactive zones, bulk membrane reuptake, and fast recycling at the AZ (Klingauf et al., 1998; Richmond and Broadie, 2002; Harata et al., 2006; He and Wu, 2007; Smith et al., 2008; Rizzoli, 2014). Several studies suggest that evoked and spontaneous modes of release may use different recycling pathways (Sara et al., 2005; Kavalali et al., 2011; Ramirez and Kavalali, 2011; Peng et al., 2012; Melom et al., 2013; Reese and Kavalali, 2015; Cork et al., 2016). However, it is still debated whether the recycling vesicle pools used for evoked and spontaneous release can intermix (Groemer and Klingauf, 2007; Hua et al., 2010; Schneggenburger and Rosenmund, 2015). In addition, it is not yet understood how coupling between the processes of exocytosis and endocytosis occurs.

Neurotransmission is dynamic and plastic, and it is still debated how endocytic mechanisms respond to adjust to modified exocytosis rates. Evoked exocytosis is triggered by $\mathrm{Ca}^{2+}$ inflow into nerve terminals, and several studies indicate that $\mathrm{Ca}^{2+}$ may accelerate endocytosis (Leitz and Kavalali, 2016). However, some forms of endocytosis are not promoted by calcium (Wu and Betz, 1996; Cousin and Robinson, 2000). Furthermore, it remains unclear how vesicle retrieval is adjusted when exocytosis is promoted in a calcium-independent way.

Vesicle fusion is controlled by the SNARE complex, which mediates the attachment of vesicles to the plasma membrane (Südhof, 2013a). A small cytosolic protein complexin (Cpx) binds to the SNARE complex, promoting evoked fusion (Reim et al., 2001; Xue et al., 2008, 2010) and inhibiting spontaneous release (Huntwork and Littleton, 2007; Yang et al., 2010, 2013). These two Cpx functions are controlled by different molecular mechanisms (Xue et al., 2007, 2009; Cho et al., 2010, 2014), and the inhibition of spontaneous release by Cpx is most prominent at invertebrate synapses (Huntwork and Littleton, 2007; Martin et al., 2011; Jorquera et al., 2012; Wragg et al., 2013).

In the present study, we took advantage of $C p x$ null $\left(c p x^{-1-}\right)$ Drosophila neuromuscular junctions (NMJs) to investigate the coupling between spontaneous exocytosis and vesicle recycling. Spontaneous exocytosis is increased manyfold at $c p x^{-1-}$ NMJs (Huntwork and Littleton, 2007; Jorquera et al., 2012), providing excellent experimental conditions for investigating synaptic vesicle recycling during spontaneous activity. Because the loss of complexin promotes spontaneous release selectively and in a $\mathrm{Ca}^{2+}$-independent manner (Jorquera et al., 2012), $c p x^{-1-}$ NMJs enable the characterization of vesicle recycling mechanisms activated in response to enhanced $\mathrm{Ca}^{2+}$-independent fusion. We used EM analysis and photoconversion of the lipophlic dye FM1-43, combined with electrophysiology, to investigate spontaneous and evoked vesicle recycling pathways at $c p x^{-/-}$NMJs.

\section{Materials and Methods}

Fly stocks. Drosophila melanogaster of either sex were cultured on standard medium at $22^{\circ} \mathrm{C}$. The following fly stocks were used: Canton S (WT, Bloomington stocks, RRID:FlyBase_FBst1000081), $c p x^{S H 1}\left(c p x^{-/-}\right)$ (Huntwork and Littleton, 2007), HB mCpx I UAS-transgene rescue expressed using the pan-neuronal elav ${ }^{\mathrm{C} 155}$-gal4 driver in the $c p x^{-1-}$ background (Cho et al., 2014), and the paralytic syntaxin mutant $s y x^{3-69}$ (Littleton et al., 1998).
FM1-43 imaging. Experiments were performed at Ib boutons of muscles 6 and 7 at abdominal segments $2-4$ of wandering third instar larvae in HL3 solution, containing the following (in $\mathrm{mM}$ ): $70 \mathrm{NaCl}, 5 \mathrm{KCl}, 20$ $\mathrm{MgCl}_{2}, 1 \mathrm{CaCl}_{2}, 10 \mathrm{NaHCO}_{3}, 5$ trehalose, 115 sucrose, 2.5 HEPES-HCl, and 2.5 HEPES-NaOH, pH 7.2-7.4) at $25^{\circ} \mathrm{C}$. Dye loading was done with $2.5 \mu \mathrm{M}$ FM1-43 (Invitrogen) added. Stimulation was performed via a suction electrode at a frequency of $5 \mathrm{~Hz}$. Upon dye loading, preparations were briefly washed in $\mathrm{Ca}^{2+}$-free HL3 saline containing $75 \mu \mathrm{M}$ Advasep-7 (Biotium) to reduce background fluorescence. Image acquisition was performed using a real-time laser-based confocal unit (PerkinElmer Life Sciences) equipped with a CCD camera (ORCA ER, Hamamatsu). Confocal $z$-stacks of images were acquired at $1 \mu \mathrm{m}$ steps using a $60 \times$ water-immersion objective (Zeiss) and analyzed as $3 \mathrm{D}$ volumes using Volocity software (Improvision) as described previously (Akbergenova and Bykhovskaia, 2007).

$E M$. The sample preparation protocol was modified from a prior study (Akbergenova and Bykhovskaia, 2009b). Preparations were fixed in $4 \%$ PFA, $2.5 \%$ glutaraldehyde, and $0.2 \mathrm{mM} \mathrm{CaCl}_{2}$ in $0.9 \mathrm{~mm}$ cacodylate buffer, $\mathrm{pH} 7.4$, in a microwave oven (Biowave, Ted Pella) at $250 \mathrm{~W}$, $30^{\circ} \mathrm{C}-32^{\circ} \mathrm{C}$ for $2 \mathrm{~min}$, and then kept in the same fixative at a room temperature for $15 \mathrm{~min}$. Then preparations were washed in cacodylate buffer and postfixed for $1 \mathrm{~h}$ in $1 \%$ osmium tetroxide. The samples were further contrasted in $2 \%$ uranyl acetate for $30 \mathrm{~min}$ and dehydrated in a graded series of acetone and water mixtures up to $100 \%$ acetone. Specimens were embedded in Embed 812 epoxy resin overnight at $60^{\circ} \mathrm{C}$ (Electron Microscopy Sciences). Preparations were serially sectioned (50 nm thick) using a Leica Ultracut ultramicrotome and visualized using a JEOL 100 CX electron microscope equipped with a Hamamatsu digital camera and AMT software.

The analysis of micrographs was performed using ImageJ (National Institutes of Health) and Adobe Photoshop (Adobe Systems) software. The distribution of synaptic vesicles in Ib boutons was analyzed from micrographs at $\times 7000$ and $\times 14,000$ magnification. The area occupied by vesicles was determined as previously described (Akbergenova and Bykhovskaia, 2009b, 2010). Vesicle distribution around AZs was analyzed from serial sections. We have included in the analysis only those AZs for which all the serial sections were collected. Vesicles were classified according to their position at the T-bar and the plasma membrane.

FM1-43 photoconversion. The photoconversion procedure was modified from a prior study (Akbergenova and Bykhovskaia, 2009a). FM1-43 $(10 \mu \mathrm{M})$ was used to load the preparations. Subsequently, preparations were fixed in $4 \%$ PFA, $0.1 \%$ glutaraldehyde, and $0.2 \mathrm{mM} \mathrm{CaCl}_{2}$ in $0.9 \mathrm{~mm}$ cacodylate buffer, $\mathrm{pH}$ 7.4, for $15 \mathrm{~min}$ at room temperature and washed in HEPES-buffered saline (in $\mathrm{mM}$ ) as follows: 20 HEPES, 145 $\mathrm{NaCl}, 0.2 \mathrm{CaCl}_{2}, \mathrm{pH}$ 7.2. Samples were preincubated for $10 \mathrm{~min}$ in 1.5 $\mathrm{mg} / \mathrm{ml} \mathrm{DAB}$ (Dako) in HEPES-buffered saline and illuminated for $9 \mathrm{~min}$ under a $60 \times$ water-immersion objective using a mercury lamp with a $480 \pm 10$ bandpass excision filter. The preparations were processed for conventional EM as described above.

Electrophysiology. Electrophysiological analysis was performed in Drosophila HL3.1 saline adjusted to $\mathrm{pH} 7.2$ containing the following (in $\mathrm{mm}$ ): $70 \mathrm{NaCl}, 5 \mathrm{KCl}, 4 \mathrm{MgCl}_{2}, 10 \mathrm{NaHCO}_{3}, 5$ Trehalose, 115 sucrose, 5 HEPES-NaOH, and $0.3 \mathrm{Ca}^{2+}$. Evoked excitatory junctional potentials (EJPs) were recorded intracellularly from muscle fiber 6 of segment A3 using an Axoclamp 2B amplifier (Molecular Devices). Data acquisition was performed using Clampex 9.0 software (Molecular Devices) as previously described (Cho et al., 2010). Bafilomycin (Baf, $4 \mu \mathrm{M}$ in HL3.1; LC Laboratories) was bath applied to dissected larvae and incubated for 10 min. Nerve stimulation at $0.5 \mathrm{~Hz}$ in each experiment was performed using a programmable stimulator before and after Baf application (Master-8; AMPI). Minis and EJPs were analyzed using Mini Analysis 6.0.3 (Synaptosoft; RRID:SCR_002184) and Clampfit 9.0 (RRID: SCR_011323) software as previously described (Cho et al., 2010). The detection parameters were adjusted at traces with clearly detectable minis recorded from WT preparations, and the traces recorded at different conditions were analyzed blindly.

Immunostaining. Control and $c p x^{S H 1}$ mutant third instar larvae were stained as previously described (Rodal et al., 2008; Stevens et al., 2012). Briefly, fixations using the synaptogyrin antibody (anti-Gyrin) were per- 

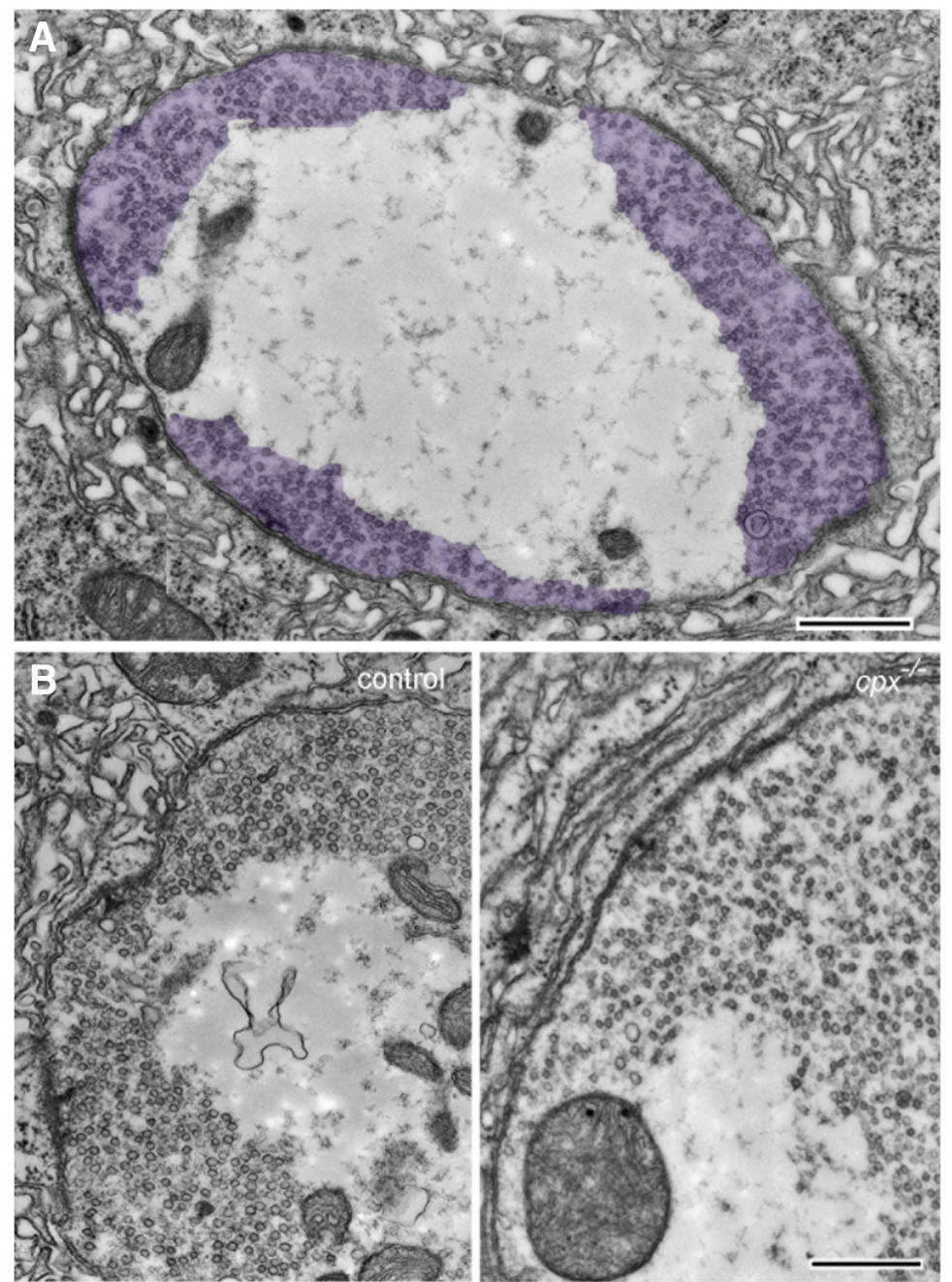

C

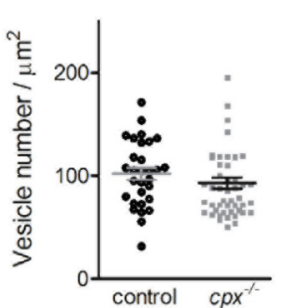

E

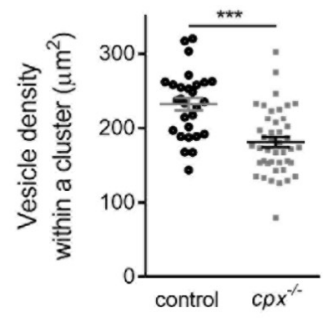

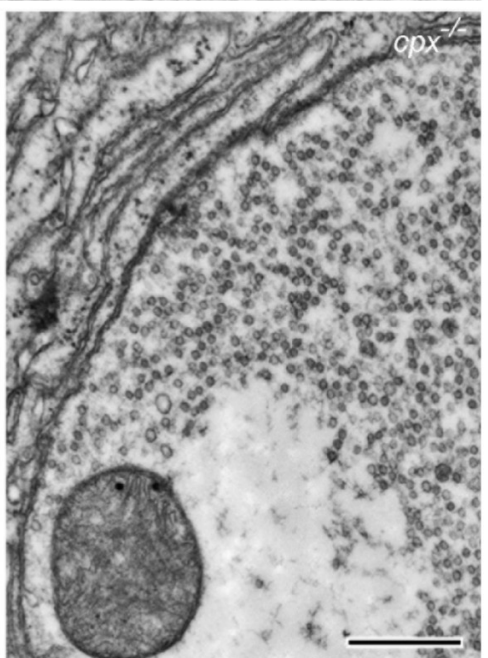

D

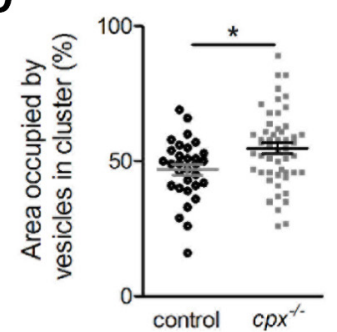

$\mathbf{F}$

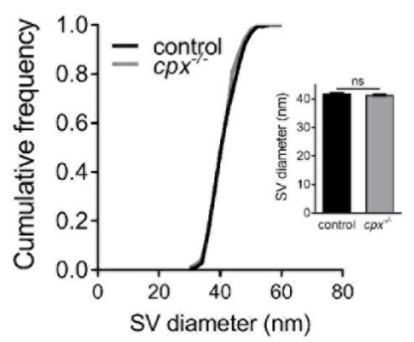

Figure 1. Cpx deletion does not produce a depletion of synaptic vesicles but promotes vesicle dispersion. $\boldsymbol{A}, 0$ utline of the area of peripherally clustered vesicles (purple shading). Scale bar, $0.5 \mu \mathrm{m}$. B, Representative micrographs of WT and $\mathrm{cpx}^{-1-}$ synaptic boutons. Vesicles are densely packed over the periphery of the WT bouton and are dispersed in the $c p x^{-1-}$ bouton. Scale bar, $0.5 \mu \mathrm{m}$. $\boldsymbol{C}$, Vesicle numbers are unaltered in $c p x^{-1-}$ boutons. $\boldsymbol{D}$, The area occupied by the peripheral vesicle cluster is significantly increased in $\mathrm{cpx}^{-/-}$boutons. $\boldsymbol{E}$, Synaptic vesicle density within the peripheral vesicle cluster is significantly reduced in $c p x^{-1-}$ boutons. $\boldsymbol{F}$, Synaptic vesicle size is not altered by Cpx deletion $(n=300)$. Data collected from 42 WT and $44 c p x^{-1-}$ boutons (4 larvae for each line). ${ }^{*} p<0.05 .{ }^{* *} p<0.001$.

formed for $5 \mathrm{~min}$ in ice-cold $100 \%$ methanol. Fixations using NWK (anti-NWK, RRID: AB_2569355) and bruchpilot (BRP, nc82, RRID: AB_2314866) antibodies were performed for 45 min using in HL3.1 containing 4\% formaldehyde. Primary antibody dilutions were as follows: anti-BRP (nc82, DSHB), 1:100; anti-Gyrin, 1:500 (Stevens et al., 2012); and anti-NWK, 1:1000 (Rodal et al., 2008). Secondary antibodies were used at a dilution of 1:500 and included AlexaFluor488-conjugated goat anti-rabbit, AlexaFluor-546conjugated goat anti-mouse (Invitrogen, RRID: AB_143165, RRID:AB_141370), and AlexaFluor488-conjugated goat anti-mouse (Invitrogen, RRID:AB_143160). Images were acquired with a LSM 700 confocal microscope using Zen software (Carl Zeiss MicroImaging).

Calcium imaging. The $\mathrm{Ca}^{2+}$ imaging experiments were performed as described by Karunanithi et al. (1997). Briefly, stock solution of Fluo 4 AM (Invitrogen) was dissolved in DMSO and kept at $-20^{\circ} \mathrm{C}$. Final concentration of Fluo $4 \mathrm{AM}$ in the bath was $12 \mu \mathrm{M}$. The dye was loaded by incubating preparations at room temperature in the dark. Image acquisition was performed using the real-time confocal microscope (PerkinElmer Life Sciences, $\times 60$ waterimmersion objective). The preparations were imaged at rest, and then the imaging session was repeated during the stimulation at a $30 \mathrm{~Hz}$ frequency for $10 \mathrm{~s}$.

Statistical analysis. Unpaired two-sided $t$ test, one-way ANOVA with post hoc Tukey analysis, and Shapiro-Wilk normality test were performed for dataset comparisons.

\section{Results}

Spontaneous release is enhanced $\sim 70$ fold at Drosophila 1b boutons in complexin null mutants $\left(c p x^{S H 1}\right)$ (Bykhovskaia et al., 2013), prompting the question of how nerve terminals maintain this drastically elevated activity. We first assayed whether enhanced spontaneous release depletes synaptic vesicles by performing EM analysis and calculating the overall vesicle density within the entire bouton, the area occupied by a peripheral vesicle cluster (Akbergenova and Bykhovskaia, 2009b), as well as the vesicle density within these clusters (Fig. $1 A$ ). We found no change in overall vesicle density per individual bouton in $c p x$ null mutants compared with control (Fig. $1 B, C$ ). Although the overall vesicle density was unchanged in $c p x^{-1-}$ boutons (Fig. $1 C$ ), the area of vesicle clusters was larger in $c p x^{-1-}$ than controls (Fig. 1D). Moreover, synaptic vesicles were more dispersed in $c p x^{-1-}$ boutons compared with controls, as reflected by a decrease in vesicle density within a cluster (Fig. 1E). The unchanged synaptic vesicle numbers (Fig. $1 C$ ) indicate that endocytosis is enhanced to compensate for the elevated rate of spontaneous fusion events in $c p x^{-/-}$. 

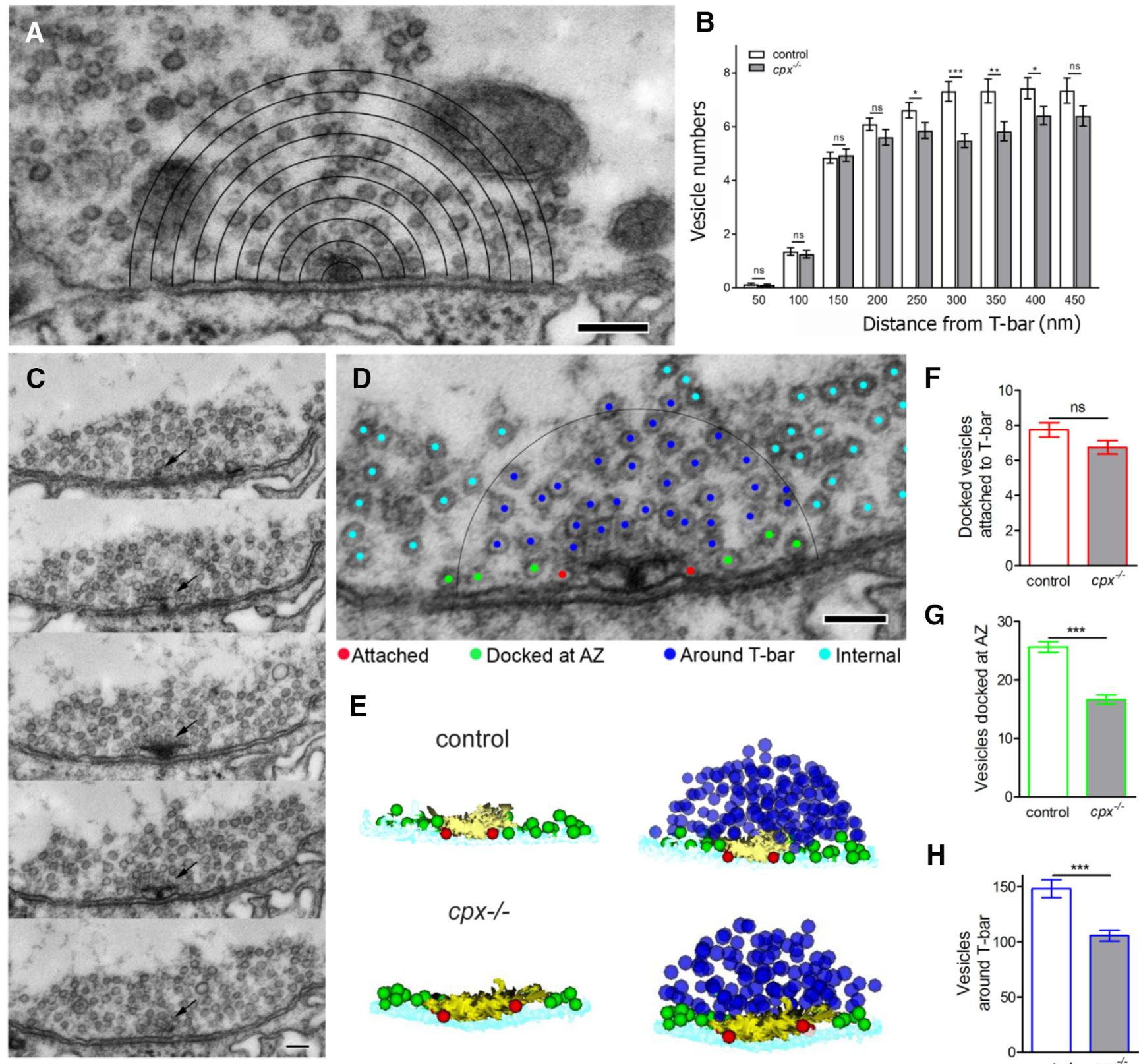

\section{G}
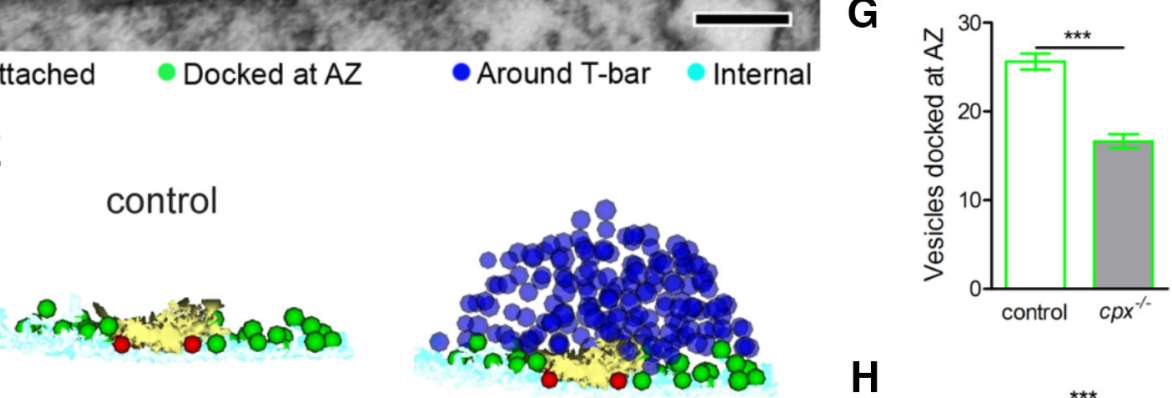

H
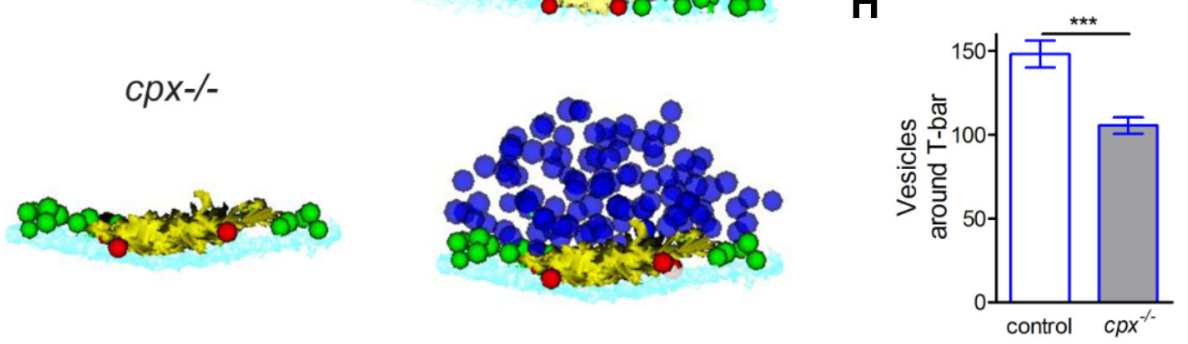

Figure 2. Selective depletion of docked vesicles in the vicinity of T-bars in $\mathrm{cpx}^{-1-}$ boutons. $A$, Micrograph illustrating morphometric analysis of vesicle numbers at different layers surrounding the T-bar. Scale bar, $150 \mathrm{~nm} . \boldsymbol{B}$, In cpx ${ }^{-1-}$ boutons, vesicle numbers are unaltered in the immediate proximity to T-bars $(50-200 \mathrm{~nm})$ but significantly depleted at a distance of $250-400 \mathrm{~nm}$ from the T-bar. C, Subsequent serial sections showing an AZ (arrow) with a T-bar at the synaptic membrane surrounded by vesicles. Scale bar, $100 \mathrm{~nm}$. D, Micrograph illustrating the vesicle classification according to their position at the T-bar: docked and attached to the T-bar ("Attached," red); docked in the vicinity of the T-bar but not attached to it ("Docked at AZ," green); around the T-bar ("Around T-bar," within a $150 \mathrm{~nm}$ radius outlined by the black circle, blue); intraterminal vesicles not situated in the vicinity or around T-bars ("Internal," cyan). Scale bar, $100 \mathrm{~nm}$. C,3D reconstruction of a T-bar surrounded by vesicles shows a selective depletion in the pool of vesicles docked at AZ (green) and around T-bar (blue). For clarity, left panels for control and cpx ${ }^{-1-}$ AZs represent only the T-bar with docked vesicles. $\boldsymbol{F}-\boldsymbol{H}$, Vesicle numbers quantified from 3 D reconstructions. $\boldsymbol{D}$, The number of attached vesicles (red) is unaffected by Cpx deletion. $\boldsymbol{E}$, The number of vesicles docked at AZ (green) is reduced in $c p x^{-1-}$ boutons. $G$, The number of vesicles around T-bar are reduced in $c p x^{-1-}$ boutons. All the vesicles for each AZ are counted from complete $3 \mathrm{D}$ reconstructions of AZs. Data collected from 56 WT and $57 \mathrm{cpx}{ }^{-I-}$ AZs (4 larvae for each line). ${ }^{* * *} p<0.001$.

Furthermore, the change in synaptic vesicle density within clusters (Fig. $1 D$ ) in $\mathrm{cpx}^{-1-}$ suggests alterations in vesicle recycling pathways. To test whether the process of vesicle formation during endocytosis may be altered, we compared the size of synaptic vesicles in WT and $c p x^{-1-}$ boutons (Fig. $1 F$ ). The cumulative distributions and average vesicle diameters were similar in both lines, suggesting that the process of vesicle budding is not altered by Cpx deletion. These results support the hypothesis that the recycling pool of vesicles may be increased in $c p x^{-1-}$ boutons to enable multiple spontaneous fusion events. Alternatively, the speed of the endocytic process may be increased in the mutant. To investigate these possibilities, we performed a more detailed analysis of vesicle distribution and combined it with labeling of the recycling pool.

First, we quantified vesicles surrounding AZs. At Drosophila motor boutons, AZs are represented by filamentous structures (T-bars) attached to the synaptic membrane and surrounded by vesicles. T-bars function to organize $\mathrm{Ca}^{2+}$ channels and other elements of AZs to achieve the precision and speed necessary for efficient neurotransmission (Owald and Sigrist, 2009). We inves- 


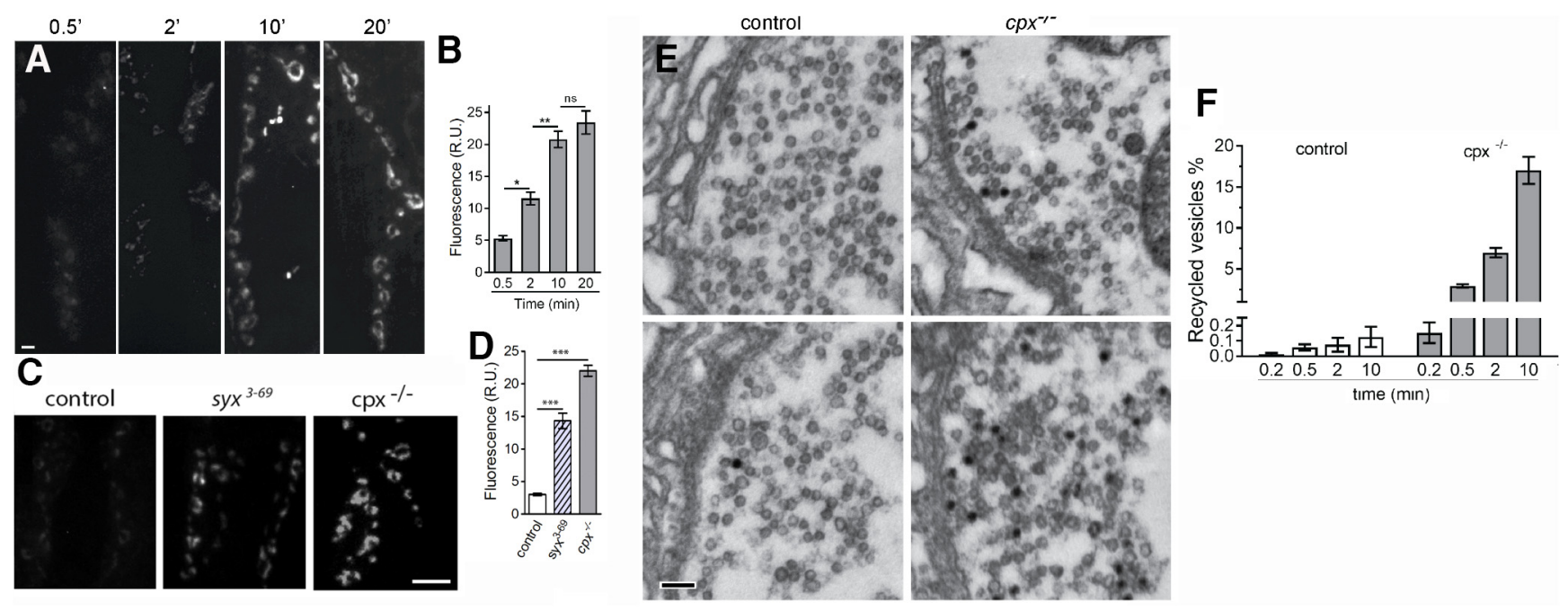

Figure 3. Increased spontaneous activity in $c \mathrm{px}^{-1-}$ boutons drives an increase in the recycling pool of vesicles. $A$, Preparations passively loaded with FM1- 43 dye after different times of dye exposure. Images represent overlay of confocal $z$-stacks. There is very faint fluorescence at $0.5 \mathrm{~min}$ loading, which is increased at $10 \mathrm{~min}$ loading, but not increased further at $20 \mathrm{~min}$ loading. Scale bar, $5 \mu \mathrm{m}$. $\boldsymbol{B}$, Fluorescence intensity measured over confocal stacks at $c p x^{-1-}$ preparations. No increase in the fluorescence is observed after 10 min loading, suggesting that the recycling vesicle pool reached its maximal capacity. Data collected from at least 70 boutons (4 larvae) for each data point. C, Overlays of confocal stacks showing WT, syx ${ }^{3-69}$, and $c p x^{-1-}$ preparations loaded passively with FM1-43 for $10 \mathrm{~min}$. Scale bar, $10 \mu \mathrm{m}$. D. Florescence intensity of WT, syx $x^{3-69}$, and $c p x^{-1-}$ preparations passively loaded for 10 min shows a significantly higher fluorescence for $\mathrm{cpx}^{-1-}$ preparations, and for syx ${ }^{3-69}$ boutons, suggesting an increased recycling pool. Data collected from at least 30 boutons (4 larvae) for each genotype. $\boldsymbol{E}$, Electron micrographs obtained after FM1- 43 photoconversion show recycled (black) and nonrecycled (translucent) vesicles in WT and cpx ${ }^{-1-}$ boutons after 0.5 (top) and 10 (bottom) min passive FM1- 43 loading. Scale bar, 200 $\mathrm{nm} . \boldsymbol{F}$, The number of recycled vesicles in WT and $c p x^{-1-}$ boutons. Vesicles are quantified from electron micrograph obtained using FM1-43 photoconversion at dye loading times and in the absence of stimulation. Data collected from at least 10 boutons (3 larvae) for each data point. ${ }^{*} p<0.05 .{ }^{* *} p<0.01 .{ }^{* * *} p<0.001$.

tigated how Cpx deletion affects the numbers of vesicles at different layers surrounding T-bars (Fig. 2A). Interestingly, we discovered that $c p x^{-1-}$ boutons have significant depletion of vesicles in the vicinity of T-bars (at a distance of $250-400 \mathrm{~nm}$; Fig. $2 B$ ), but not in the immediate proximity to $\mathrm{T}$-bars (there are similar vesicle numbers at a distance of $0-200 \mathrm{~nm} ; \mathrm{Fig} .2 B$ ). This finding suggests that either vesicle docking or local recycling at AZs can be altered in $c p x^{-/-}$boutons.

To examine this phenomenon more closely, we performed 3D reconstruction of all serial sections containing individual T-bars (Fig. 2C). Vesicles surrounding T-bars were quantified from $3 \mathrm{D}$ reconstructions. The vesicles situated within $300 \mathrm{~nm}$ from a T-bar (Fig. 2D, black semicircle) were classified and subdivided into the following spatially restricted volumes: (1) vesicles docked and attached to T-bar ("Attached," Fig. 2D, red) which are likely to colocalize with $\mathrm{Ca}^{2+}$ channels; (2) vesicles docked near a T-bar but not attached to it ("Docked at AZ," Fig. 2D, green), which may be released in a $\mathrm{Ca}^{2+}$-independent mode; and (3) vesicles surrounding a T-bar but not docked to the membrane ("Around T-bar," Fig. 2D, blue) which may replenish either of the two pools of docked vesicles. Vesicles outside of a $300 \mathrm{~nm}$ T-bar radius were classified as "Internal" (Fig. 2D, cyan). Synaptic vesicles found in these spatially restricted volumes may reflect various stages of preparation for the release process. Attached vesicles are situated in close proximity to $\mathrm{Ca}^{2+}$ channels and probably constitute the readily releasable pool responding to action potentials (Hallermann et al., 2010). Docked at AZ vesicles may be available for $\mathrm{Ca}^{2+}$-independent release, whereas those around the T-bar may require additional priming and docking reactions before release (Jiao et al., 2010; Hallermann and Silver, 2013).

Upon quantification of vesicles in each spatially defined volume, we did not observe any significant change in the number of attached vesicles in $c p x^{-1-}$ boutons compared with WT (Fig. $2 E, F$, red), consistent with earlier studies (Jorquera et al., 2012).
However, the number of vesicles docked at the AZ (Fig. 2D,E, green) was significantly reduced in $c p x^{-1-}$ boutons compared with WT (Fig. 2G). The specific depletion of docked at AZ vesicles in $c p x^{-1-}$ suggests that spontaneous release events, which are massively enhanced in $c p x^{-/-}$, may occur independently and proximal to the core T-bar machinery. In addition, the pool of vesicles around the T-bar (Fig. 2D,E, blue) was also reduced in $c p x^{-1-}$ boutons (Fig. $2 H$ ), suggesting that the process of vesicle mobilization or recycling may be altered.

To investigate vesicle recycling in $c p x^{-/-}$boutons, we used the activity-dependent lipophilic marker FM1-43 that can be used to monitor retrieved synaptic vesicles (Cochilla et al., 1999; Ryan, 2001). First, we investigated vesicle recycling during spontaneous activity, using passive dye loading performed in the absence of stimulation. In $c p x^{-1-}$ boutons, the FM1-43 fluorescence increased consistently as the dye was loaded passively in the absence of stimulation for $0.5,2$, and $10 \mathrm{~min}$ (Fig. $3 A, B$ ). After 10 min of loading, a plateau was reached, and increasing the loading time to $20 \mathrm{~min}$ did not produce any further increase in FM1-43 fluorescence in $c p x^{-1-}$ (Fig. $3 A, B$ ). The loading kinetics suggests that, after $10 \mathrm{~min}$, the recycling pool is fully labeled; thus, exocytosis is supplied by the labeled vesicle pool, which does not increase further.

In WT preparations, passive FM1-43 loading produced very weak FM1-43 staining, which was only slightly above the background even after $10 \mathrm{~min}$ of loading (Fig. $3 C, D$ ). These results demonstrate that substantial recycling of vesicles occurs in $c p x$ null NMJs, which is not observed in NMJs exhibiting normal spontaneous release rates, suggesting that enhanced spontaneous exocytosis in the $c p x^{-1-}$ mutant elicits enhanced reuptake. However, we cannot rule out the possibility that $\mathrm{Cpx}$ contributes to spontaneous endocytosis directly and that Cpx deficiency compromises vesicle recycling. To test whether this may be the case, we accessed spontaneous FM1-43 loading in the syntaxin paralytic mutant $s y x^{3-69}$ (Littleton et al., 1998), which also has en- 


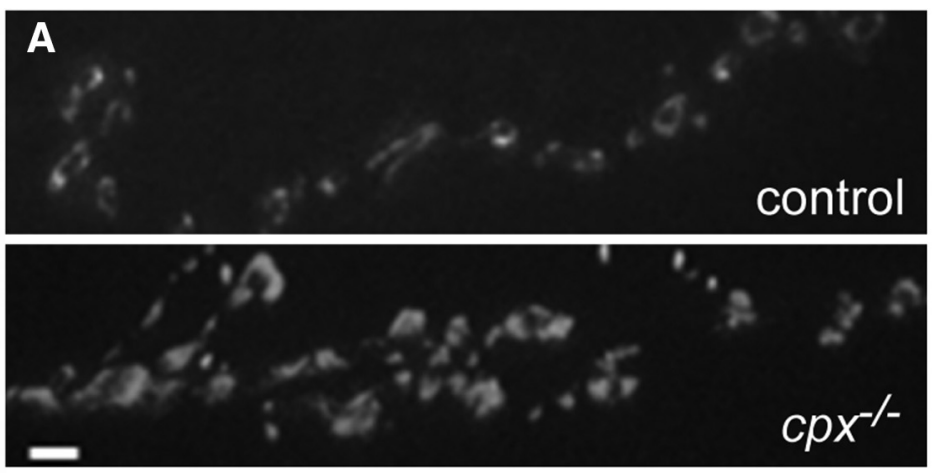

B

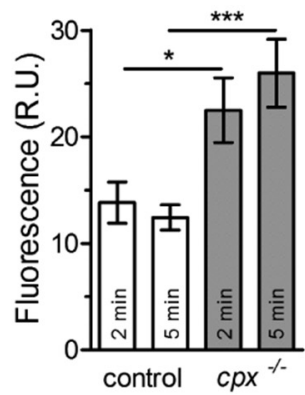

D
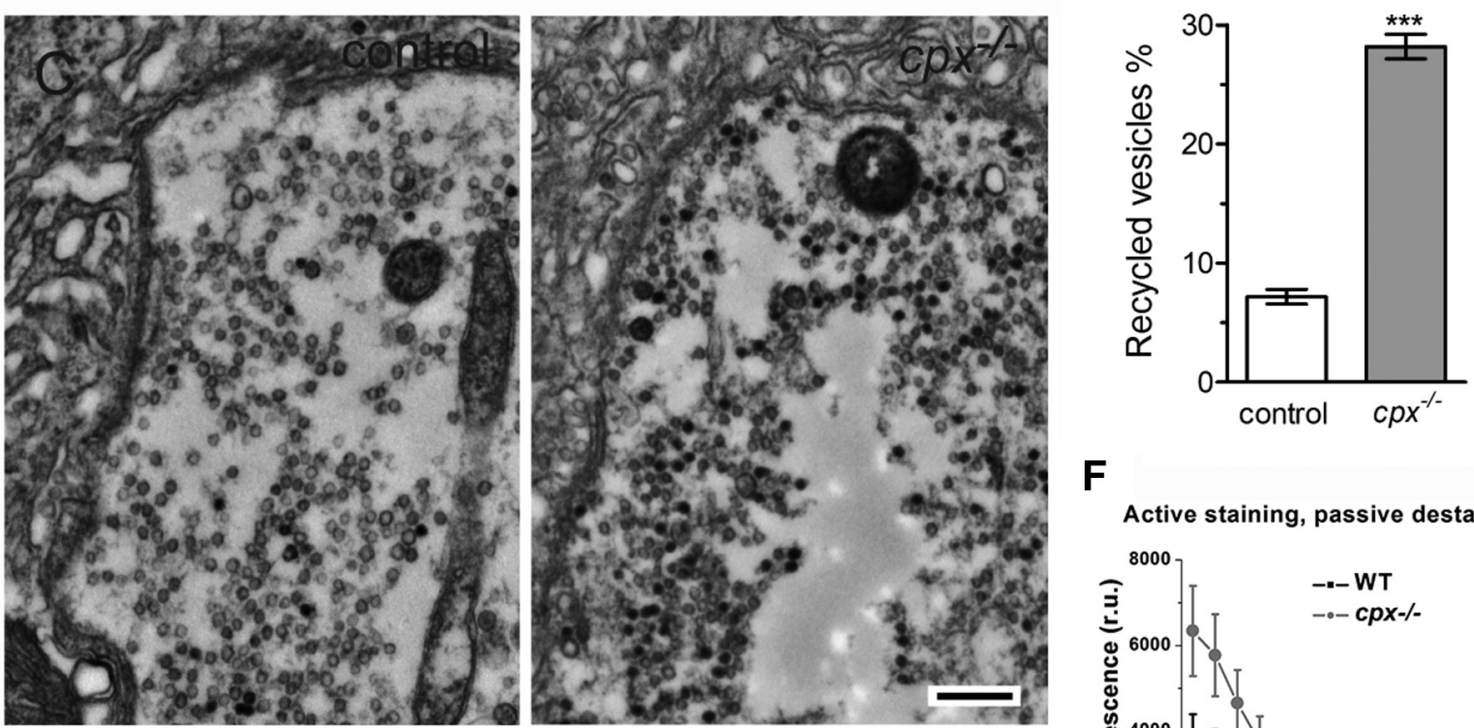

$\mathbf{F}$

Active staining, passive destaining

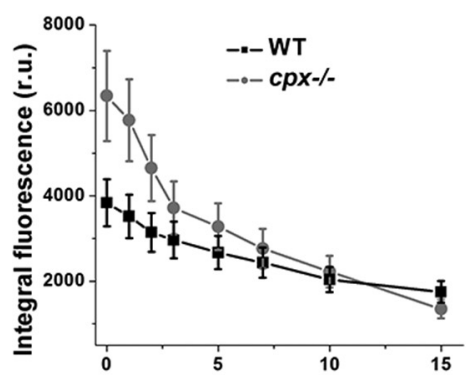

\section{E $0 \min \quad 3 \min \quad 7 \min 15 \mathrm{~min}$}
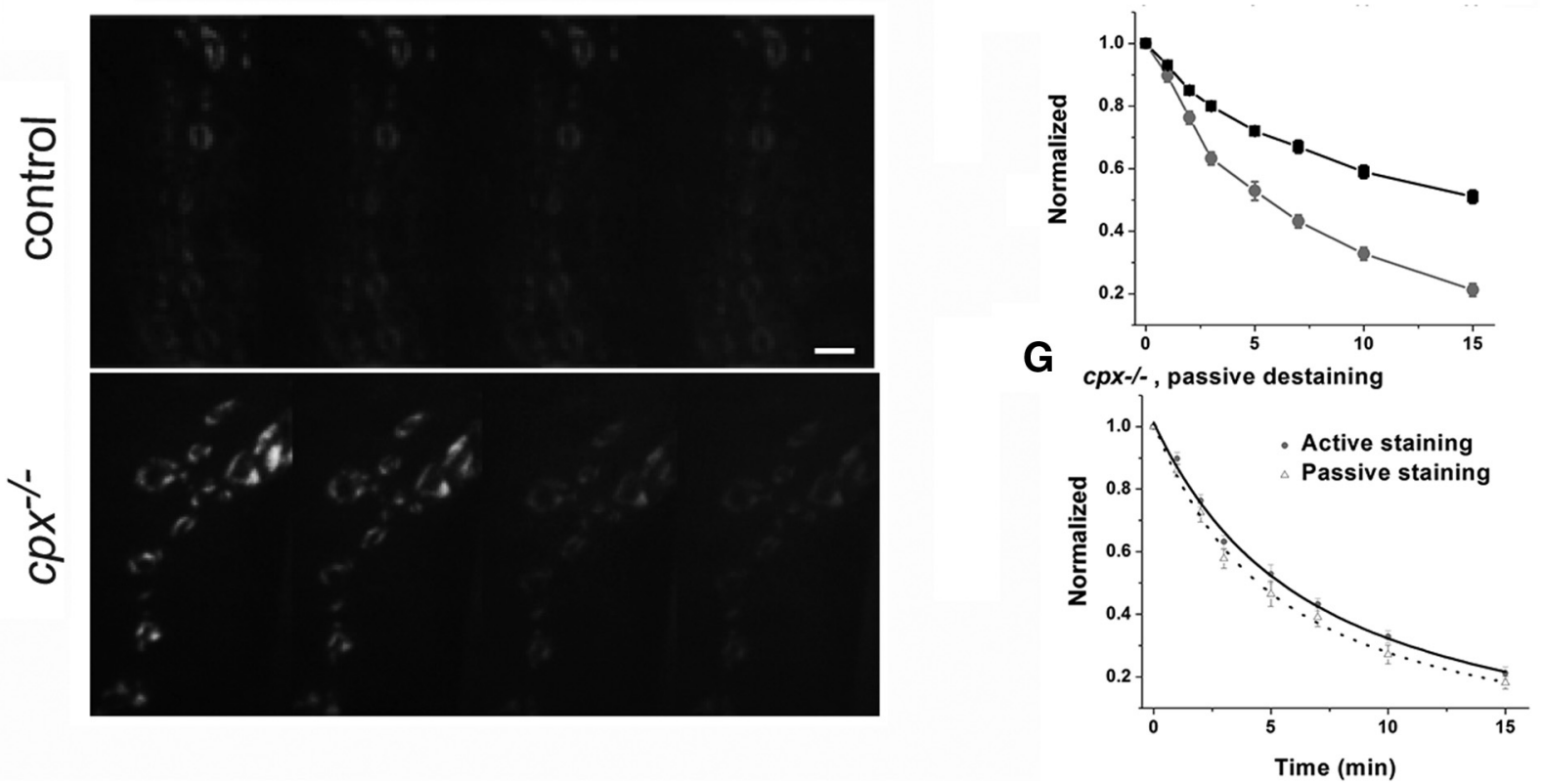

Figure 4. Active FM1-43 staining/destaining coupled with dye photoconversion and EM analysis suggests that the overall evoked and spontaneous recycling pathways are partially segregated in $c p x^{-1-}$ boutons. $A$, Overlay of confocal stacks showing WT and $c p x^{-1-}$ NMJs loaded with FM1-43 dye during electrical stimulation of the nerve at $5 \mathrm{~Hz}$ for 5 min. There is increased FM1-43 fluorescence in $\mathrm{cpx}^{-1-}$ boutons. Scale bar, $5 \mu \mathrm{m}$. $\boldsymbol{B}$, The FM1-43 fluorescence is increased in $\mathrm{cpx}^{-1-}$ boutons after active dye loading. In both WT (Figure legend continues.) 
hanced spontaneous release (Lagow et al., 2007). We found that spontaneous FM1-43 loading was enhanced in the $s y x^{3-69} \mathrm{mu}-$ tant compared with WT, but to a lesser extent than in $c p x^{-1-}$ (Fig. 3C,D). This result is in agreement with measurements of exocytic rates in both mutants (Bykhovskaia et al., 2013), which have shown that spontaneous transmission in the $s y x^{3-69}$ line is enhanced compared with the WT line, but to a lesser extent than in the $c p x^{-1-}$ line.

Thus, our results suggest that enhanced recycling of vesicles helps replenish the synaptic vesicle pool to maintain the high spontaneous release rates observed in the $c p x$ null. To determine whether this is the case, we performed photoconversion of internalized FM1-43 dye followed by EM analysis (Harata et al., 2001; Schikorski and Stevens, 2001). We counted vesicles that had internalized the dye (Fig. $3 E$, black) and examined it as a percentage of the total number of vesicles in the bouton (Fig. $3 F$ ). Only a few vesicles $(<0.2 \%)$ were stained in WT preparations, even after 10 min of passive loading (Fig. $3 F$, open bars), consistent with the low levels of fluorescence observed in WT (Fig. 3C.) In contrast, $\sim 3 \%$ of vesicles were stained after 0.5 min of passive loading, increasing dramatically, to $15 \%-20 \%$ after $10 \mathrm{~min}$ (Fig. 3F, closed bars). Thus, the recycling vesicle pool is drastically increased in $c p x$ null animals, positively correlating with the overall increase in the rate of spontaneous release.

We next asked whether this observed spontaneous recycling pool participates in evoked release. To address this question, we performed FM1-43 loading by stimulating the preparations at 5 $\mathrm{Hz}$ for 2 or $5 \mathrm{~min}$, followed by photoconversion and EM analysis (Fig. $4 A-D$ ). The 2 and 5 min loading times in $c p x^{-1-}$ and WT produced similar levels of FM1-43 fluorescence (Fig. 4B), suggesting that the recycling pool was fully loaded by 2 min of stimulation in both lines. However, FM1-43 fluorescence was significantly higher in $c p x^{-1-}$ boutons. It should be noted that evoked synaptic transmission is decreased in $c p x^{-1-}$ boutons (Jorquera et al., 2012); therefore, it is unlikely that the recycling pool used by the evoked release component in $c p x^{-1-}$ boutons is increased. The enhanced levels of FM1-43 uptake detected in $c p x^{-1-}$ compared with WT is likely to result from the enhanced spontaneous release component that is occurring concurrently during stimulation, reflecting an increase in the spontaneous recycling pool in $c p x^{-1-}$. This result indicates that the recycling pools contributing to evoked and spontaneous release in $c p x^{-1-}$ boutons are additive.

To quantify the recycling pool at stimulated preparations, we performed FM1-43 photoconversion for WT and $c p x^{-1-}$ prep-

$\leftarrow$

(Figure legend continued.) and $c \mathrm{px}^{-1-}$, the recycling pool is fully loaded after $2 \mathrm{~min}$ of stimulation (at $5 \mathrm{~Hz}$ ), and it is not further increased at 5 min loading. FM1 -43 fluorescence is significantly higher in $\mathrm{cpx}^{-1-}$ boutons for each of the loading times. Data collected from at least 15 boutons ( 6 larvae) for each data point. C, Electron micrographs showing an increased number of recycled (black) vesicles in the $\mathrm{cpx}^{-1-}$ bouton after active dye loading $(5 \mathrm{~min}$ at 5 $\mathrm{Hz}$ ). Scale bar, $500 \mathrm{~nm}$. D, The number of recycled vesicles determined by the dye photoconversion coupled with EM analysis is increased in $c p x^{-1-}$ boutons after active dye loading ( 5 min at $5 \mathrm{~Hz}$ ). Data collected from 20 boutons for each genotype. $E$, WT and $c p x^{-/-}$NMJs actively loaded with FM1 -43 during 5 min stimulation at a $5 \mathrm{~Hz}(0 \mathrm{~min})$ at different time points during passive destaining $(3,7$, and $15 \mathrm{~min})$. Scale bar, $5 \mu \mathrm{m}$. $\boldsymbol{F}$, The kinetics of passive destaining of actively loaded WT and $c p x^{-/-}$NMJs. There is biphasic destaining at $c p x^{-/-}$boutons, with a rapid dye loss during the initial 3 min of destaining followed by a slower destaining phase (between 3 and $15 \mathrm{~min}$ ). Data collected from 35 boutons (9 larvae) for each genotype. Normalized FM-43 destaining (botton) shows a significantly faster dye loss at $c p x^{-1-}$ preparations. $G$, The kinetics of passive destaining of $c p x^{-l-}$ preparations loaded actively $(5$ min at $5 \mathrm{~Hz}$, solid line) and passively (10 min, dotted line). Data collected from 35 boutons ( 9 larvae) for each condition. ${ }^{*} p<0.05$. ${ }^{* * *} p<0.001$. arations and visualized loaded FM1-43 by EM after 5 min of stimulation at a frequency of $5 \mathrm{~Hz}$ (Fig. 4C,D). The number of stained vesicles in $c p x^{-1-}$ boutons significantly exceeded the number of stained vesicles in control boutons (Fig. $4 D$ ). Because $<0.2 \%$ of stained vesicles in WT boutons result from spontaneous release (Fig. $4 F$ ), the observed recycled vesicles after 5 min of stimulation in WT boutons (Fig. 4D) are almost exclusively from retrieval following evoked release. Therefore, the observed difference in recycled vesicles in WT versus $c p x^{-1-}$ boutons is likely a result of the massively enhanced spontaneous release rates that occur in the $c p x$ null. This difference $(\sim 20 \%$; Fig. $4 D)$ between genotypes closely matches the size of the spontaneous recycling pool observed in the absence of stimulation (Fig. $3 F$ ). This result suggests that vesicles recycle independently following evoked and spontaneous release and that separable recycling pathways exist for these forms of neurotransmission in the cpx null.

To test whether spontaneous and evoked recycling pools remain completely separated, or whether they may become intermixed during the release process, we loaded preparations with the dye during nerve stimulation $(5 \mathrm{~min}$ at $5 \mathrm{~Hz}$ ) and monitored the kinetics of passive destaining (Fig. $4 E, F$ ). We found that destaining was significantly faster in $c p x^{-1-}$ preparations (Fig. $4 F$, the exponential decay $\tau=8.34 \pm 0.23$ for $c p x^{-/-}$vs $\tau=$ $18.82 \pm 0.61$ for WT, $p<0.001)$. This result may be interpreted as a release of the evoked recycling pool in $c p x^{-1-}$ preparations produced by enhanced spontaneous release. However, because the vesicle pool stained in $c p x^{-1-}$ during stimulation is comprised of both evoked and spontaneous recycling pools, it is also possible that a faster overall destaining kinetics in $c p x^{-1-}$ is produced by a fast initial release of vesicles retrieved though the spontaneous pathway and a subsequent slower release of the evoked recycling pool. In support of the latter interpretation, $c p x^{-1-}$ preparations (Fig. $4 F$, gray line) exhibited a biphasic destaining, where the initial phase $(0-3 \mathrm{~min}$, slope of liner regression $b=-899.4 \pm 86.9, r=-0.993)$ was significantly faster than a subsequent phase (3-15 $\mathrm{min}, b=-196.2 \pm 8.9, r=-0.997)$. During the initial phase ( 3 min of destaining), $\sim 40 \%$ of the fluorescence in $c p x^{-\prime-}$ boutons was lost, and the fluorescence of $c p x^{-1-}$ boutons became similar to that of WT boutons. This destaining kinetics can be interpreted as the fusion of the spontaneous recycling pool during the initial phase, followed by the fusion of the evoked pool during the subsequent phase. Interestingly, the slope of the second destaining phase in $c p x^{-1-}$ preparations (3-15 $\mathrm{min}, b=-196.2 \pm 8.9, r=-0.997)$ was significantly higher than that in WT preparations $(b=-101.2 \pm$ $11.2, r=-0.982$ ), suggesting a faster loss of stained vesicles even during the second phase, presumably corresponding to the release of the evoked pool. To further investigate whether the evoked and spontaneous recycling pools intermix during the release process, we compared passive destaining in $c p x^{-1-}$ preparations loaded passively $(10 \mathrm{~min})$ with the preparations loaded during the nerve stimulation ( $5 \mathrm{~min}$ at $5 \mathrm{~Hz}$ ). We found that the difference in destaining kinetics between actively and passively loaded preparations was very modest (Fig. $4 G$ ), although statistically significant $(\tau=5.13 \pm 0.18 \mathrm{~min}$ for active staining vs $\tau=$ $7.07 \pm 0.21 \mathrm{~min}$ for passive staining, $p<0.01$ ). Thus, $c p x^{-1-}$ preparations loaded actively show a somewhat slower destaining, suggesting that the evoked recycling pool is released in the spontaneous mode, but with a slower rate than the spontaneous recycling pool. Together, these results support a model that intermixing of the spontaneous and evoked vesicle pools does occur during the release phase, although it is likely that the intermixing is partial. 
To further examine whether evoked and spontaneous recycled vesicles are distinctly mobilized, we took advantage of the proton pump blocker Baf. Acute Baf application inhibits vesicle refilling; thus, the degree of depression in the presence of Baf can be used to monitor loss of the recycling vesicle pool because recycled vesicles cannot participate in subsequent rounds of neurotransmitter release (Cousin and Nicholls, 1997; Akbergenova and Bykhovskaia, 2007). To test whether the spontaneous release component can deplete the evoked recycling pool, we recorded spontaneous and evoked postsynaptic responses (mEPSPs and EPSPs, respectively) using sharp electrode potential recordings from the postsynaptic muscle. After recording basal neurotransmission, we applied $\operatorname{Baf}(0.4 \mu \mathrm{M})$ for $10 \mathrm{~min}$ and then recorded additional mEPSPs and EPSPs (Fig. 5A). We reasoned if the spontaneous and evoked recycling pools intermix, the enhanced spontaneous release events in $c p x^{-1-}$ in the presence of Baf would eventually deplete the available vesicle pools, and we would observe a depression in EPSPs. In contrast, we anticipated that control NMJs would not exhibit Baf-dependent depletion due to the comparably low rate of spontaneous release events that would not deplete vesicle pools during the $10 \mathrm{~min}$ of Baf application. As predicted, control preparations did not exhibit a significant depression in either mEPSP frequency ( $4.1 \pm 0.8$ vs $4.9 \pm$ $1.0 \mathrm{~s}$ ) or EPSP amplitude (18.6 \pm 0.8 vs $21 \pm$ $0.6 \mathrm{mV}$ ) after Baf treatment (Fig. $5 A, B$, white bar). In contrast, $c p x^{-/-}$mutants exhibited an $\sim 50 \%$ decrease in mEPSP frequency $(46.1 \pm 3.5$ vs $87.9 \pm 4.4 \mathrm{~s})$ and an $\sim 35 \%$ decrease in EPSP amplitude (9.7 \pm 0.3 vs $15.1 \pm 0.4 \mathrm{mV}$ ) after Baf treatment (Fig. $5 A, B$, gray bar). A potential confound in these experiments is that $c p x^{-1-}$ preparations have reduced evoked release (Huntwork and Littleton, 2007; Jorquera et al., 2012), and this could potentially affect the depression rates in $c p x^{-1-}$. To bypass this confound, we used a $C p x$ mutant (HB $\mathrm{mCpx} I$ ) that has normal evoked release but maintains highly elevated spontaneous release rates (Cho et al., 2014) (Fig. 5A). HB Cpx mutants exhibited Baf-dependent depression similar to the cpx null $(36.9 \pm 4.6 \mathrm{vs}$ $85.9 \pm 6.4 \mathrm{~s}$ mEPSP frequency, and $13.7 \pm$ 0.3 vs $20.3 \pm 0.9 \mathrm{mV}$ EPSP amplitude). Together, these results suggest that the elevated spontaneous release events in the cpx null and the HB Cpx line deplete the pool of vesicles available for evoked release, consistent with recycled vesicles pools intermixing and becoming available for both spontaneous and evoked release.

It should be noted that mEPSP frequency in the $c p x^{-1-}$ and HB mCpx1 lines before the treatment could be underestimated due to high release rates and a potential overlap of individual $* * * * p<0.0001$.
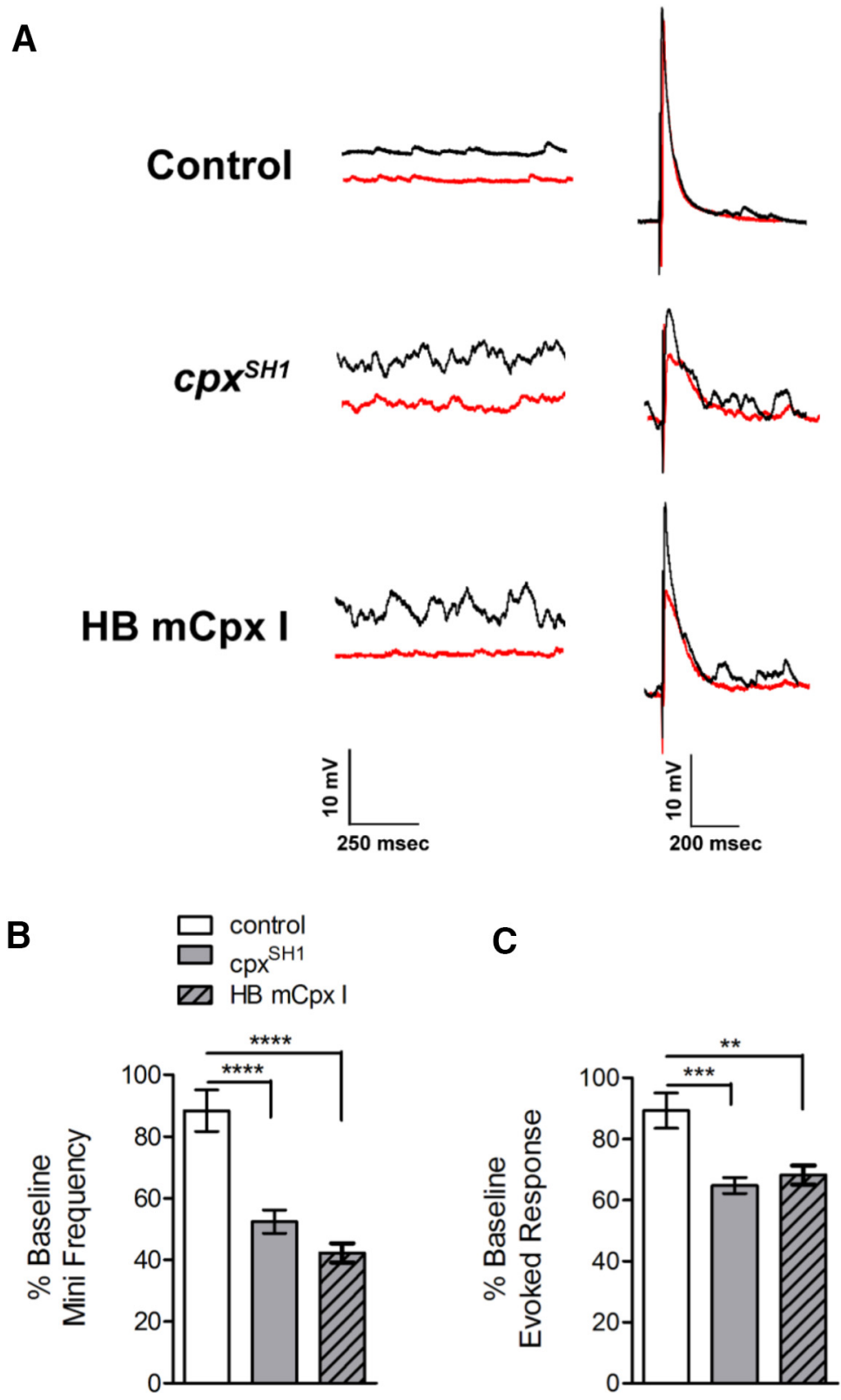

Figure 5. Spontaneous and evoked vesicles pools are depleted by the elevated spontaneous transmission in $\mathrm{cpx}^{-1-}$ and $\mathrm{HB}$ $\mathrm{mCpx}$ I lines treated with the proton pump blocker Baf. $\boldsymbol{A}$, Sample spontaneous (left) and evoked (right) traces of the indicated genotypes (Control, $c p x^{-1-}$, and HB mCpx I). After recording basal minis and EJPs (black traces), larvae were treated with $4 \mu \mathrm{m}$ Baf for $10 \mathrm{~min}$. After Baf treatment, the recordings were repeated (red lines). Post-treatment depression in both spontaneous and evoked transmission in the mutant lines but not in the control line. $B$, Spontaneous transmission is significantly reduced in cpx $^{-1-}$ and $\mathrm{HB} \mathrm{mCpx}$ I lines following Baf treatment ( $c p x^{-1-}=52.4 \pm 3.8 \%$ of basal mini frequency $[n=8]$ and $\mathrm{HB} \mathrm{mCpxI}=42.3 \pm$ $3.1 \%$ of basal mini frequency $[n=7])$. Control animals exhibit only a minor decrease $(88.4 \pm 6.7 \%$ of basal mini frequency $[n=$ 7]). C, $c p x^{-1-}$ and HB mCpx I lines exhibit a modest but significant decrease in evoked transmission following Baf treatment $\left(c p x^{-1-}=64.8 \pm 2.6 \%\right.$ of basal EPSP amplitude $[n=8]$ and HB $\mathrm{mCpx} I=68.2 \pm 8.2 \%$ of basal EPSP amplitude $\left.[n=7]\right)$. Control animals exhibited EJP amplitudes of $89.2 \pm 5.8 \%(n=7)$ compared with the basal response. Each $n$ value indicates a single muscle recording, with data generated from at least three individual larvae of each genotype. ${ }^{* *} p<0.01 .{ }^{* * *} p<0.001$.

mEPSPs, and this would produce an underestimation in the Bafdependent depression of spontaneous release. Despite that, the degree of Baf-dependent depression of spontaneous release significantly exceeded the depression observed for evoked release (Fig. $5 B, C ; 47.5 \pm 2.6 \%$ for spontaneous vs $35.2 \pm 3.8 \%$ for evoked, $p<0.001)$. These results support the conclusion that the segregation of evoked and spontaneous recycling pools is only partial. 

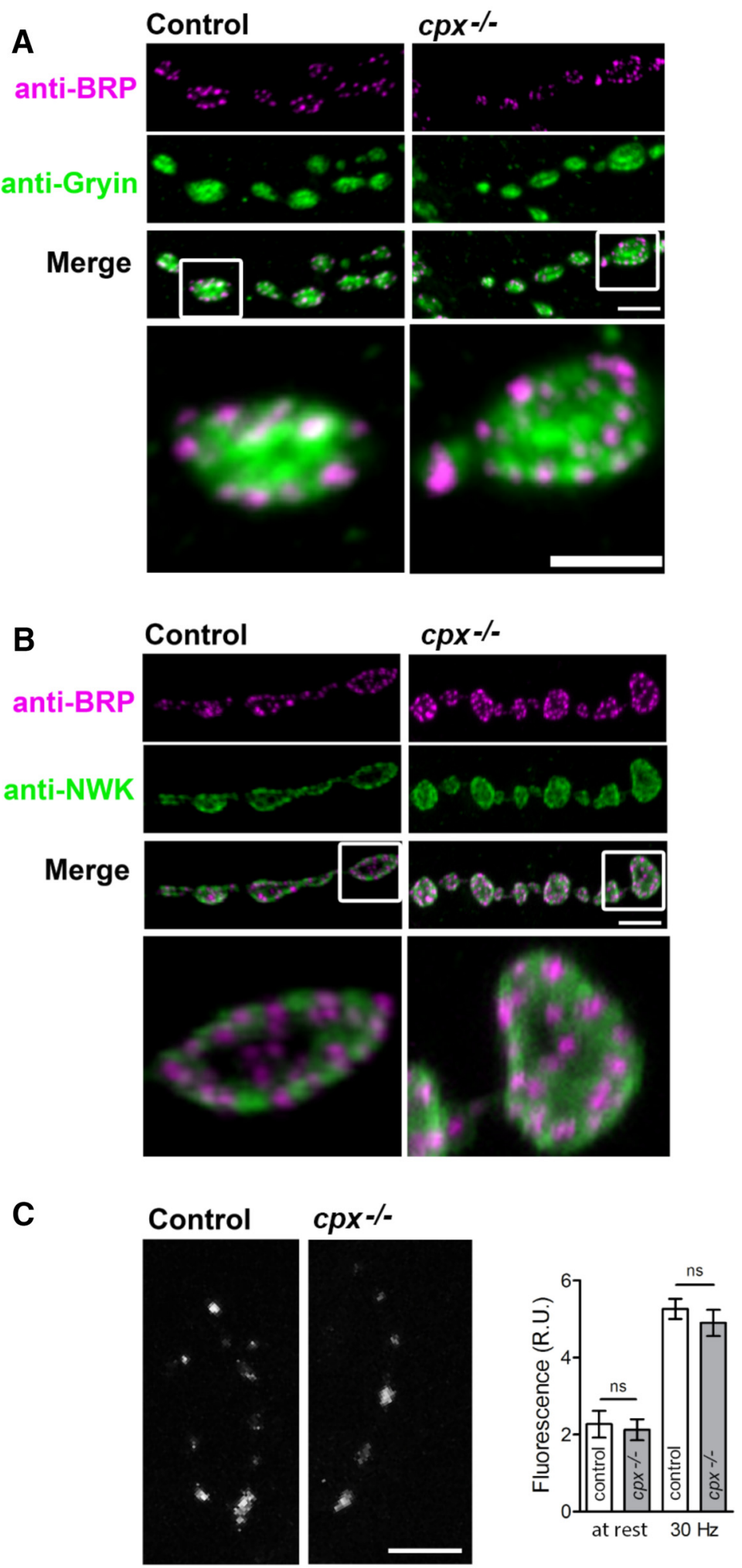

Figure 6. $c p x^{-1-}$ mutants exhibit normal synaptic architecture and calcium levels compared with controls. $A, 0$ verall distribution of AZs is unaltered in the $c p x^{S H 1}$ mutant compared with controls. Control and $c p x^{S H 1}$ mutant larval NMJs were stained with antibodies to the AZ protein, BRP (anti-NC82), and the synaptic vesicle marker, synaptogyrin (anti-gyrin). Scale bars: main, $4 \mu \mathrm{m}$; inset, $2 \mu \mathrm{m}$. B, Overall distribution of the endocytic zone marker NWK is unaltered in the $c p{ }^{S H 1}$ mutant compared with controls. Control and $c p x^{5 H 1}$ mutant larval NMJs were stained with antibodies against BRP and the periactive zone-enriched endocytic protein, NWK (anti-NWK). C, Calcium levels at rest and upon stimulation are unaltered in the cpx ${ }^{5 H 1}$ mutant compared with controls. Scale bar, $10 \mu \mathrm{m}$. Image represents terminals loaded with Fluo-4 AM during the stimulation. Graph represents Fluo-4 fluorescence intensity at rest and during the stimulation; $n=15$ for each genotype.
Together, these results suggest that $c p x^{-1-}$ terminals have an increased recycling pool of vesicles, which is comprised of partially segregated evoked and spontaneous pools. It could be suggested that the elevated spontaneous exocytosis in $c p x^{-/-}$ boutons enhances vesicle retrieval, and this process occurs independently of nerve stimulation. However, we cannot rule out the possibility that $c p x^{-1-}$ terminals have modified synaptic architecture, endocytic machinery, or $\mathrm{Ca}^{2+}$ levels, and these defects produce enhanced vesicle retrieval in the absence of stimulation. To explore this possibility, we examined synaptic architecture and $\mathrm{Ca}^{2+}$ levels in $\mathrm{cpx}^{-/-}$boutons. Immunostaining for the $\mathrm{AZ}$ marker $\mathrm{BRP}$ and the vesicle marker synaptogyrin (Gyrin) did not show any detectable alterations in the synaptic architecture of $c p x^{-1-}$ boutons (Fig. $6 A)$. Immunostaining for the endocytic periactive zone marker NWK (Rodal et al., 2008) suggested that the endocytic periactive zone is unaltered in $c p x^{-1-}$ boutons (Fig. 6B). Finally, imaging Fluo-4 AMloaded terminals indicated that similar $\mathrm{Ca}^{2+}$ levels are observed in $c p x^{-1-}$ and WT boutons at rest and during stimulation (Fig. $6 C$ ). These results support the idea that the enhanced spontaneous exocytosis observed in $c p x^{-/-}$boutons produces an increased compensatory retrieval, which does not depend on increased $\mathrm{Ca}^{2+}$ levels.

These findings suggest that evoked and spontaneous recycling pools are largely segregated during endocytosis, although they may partially intermix during the release process. To explore how the recycling pools are formed during endocytosis, we analyzed the spatial distribution of retrieved vesicles. We reasoned that different endocytic pathways are likely to produce different distributions of FM1-43-stained vesicles around AZs (Fig. $7 A$ ). In particular, fast vesicle retrieval without the loss of vesicle identity (Murphy et al., 1998; Aravanis et al., 2003) would produce preferential staining of the "Attached" vesicles (Fig. 7A1, red). In contrast, retrieval at the periactive zone followed by fast recycling (Watanabe et al., 2013a, b) would produce preferential staining of the vesicles "Around T-bar" and possibly "Docked at AZ" (Fig. 7A2, blue and green). Finally, an endocytic pathway may involve the intraterminal vesicle pool (Rizzoli and Betz, 2004, 2005), which would produce preferential staining of "Internal" vesicles (Fig. 7A3, cyan). To discriminate between these pathways, we analyzed the spatial distribution of spontaneous and evoked recycling pools. 
A
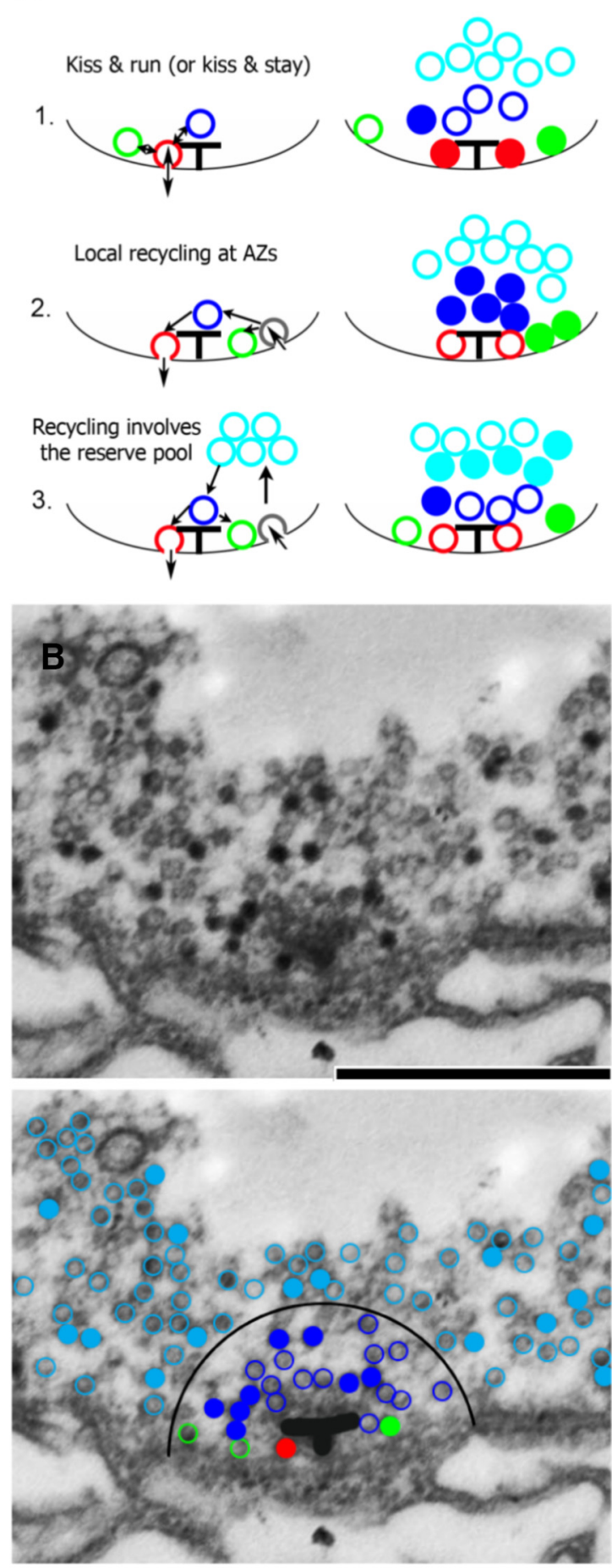

C
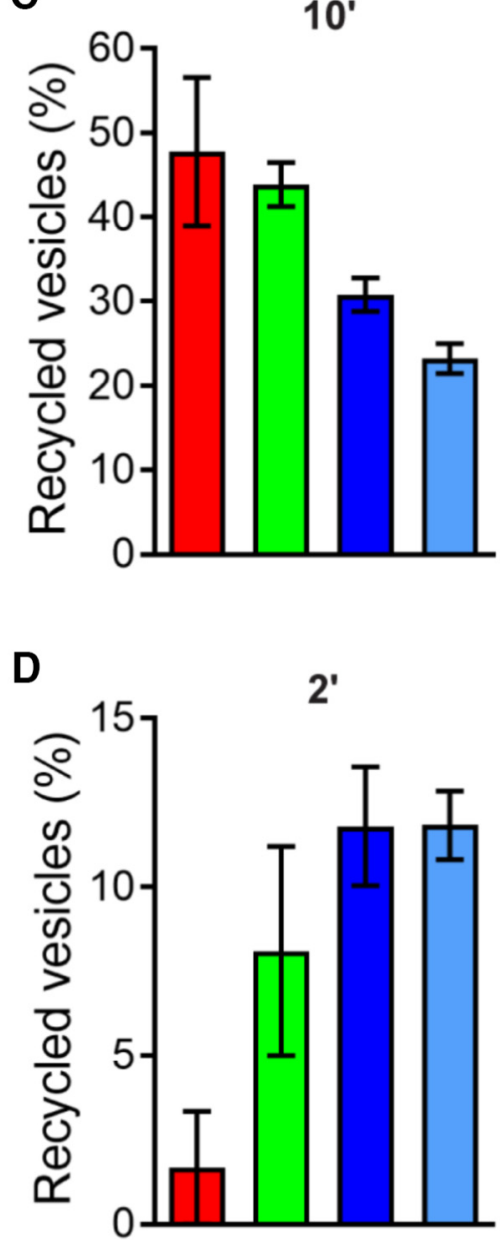

E

$\square$ Attached

$\square$ Docked at AZ

$\square$ Around T-bar

$\square$ Internal

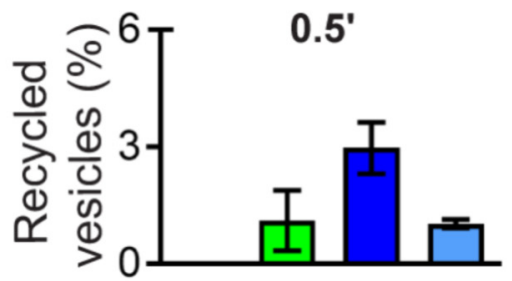

Figure 7. The spatial organization of vesicles recycled spontaneously at $c p x^{-/-}$boutons. $A$, Diagram schematically showing that different endocytic mechanism would produce different spatial distributions of recycling vesicles around AZ. A1, Vesicles recycle without losing their identity: vesicles docked and attached to T-bars (Attached, red) are fused and retrieved (kiss and run mechanism). Such a pathway would produce preferential staining of attached vesicles (right, filled red circles). A2, Vesicles are recycled at the periactive zone and are directed to AZs. Such a pathway would produce preferential staining of vesicles around T-bar and docked at AZ (right, filled blue and green circles). $\boldsymbol{A}$, Recycled vesicles are intermixed with intraterminal vesicles and subsequently directed to AZs. Such a pathway would produce preferential staining of internal vesicles (right, filled cyan circles). $\boldsymbol{B}$, Electron micrograph showing a T-bar surrounded by vesicles. The preparation was loaded with dye for $10 \mathrm{~min}$. There are stained vesicles (black), many of which surround the T-bar. Scale bar, 500 $\mathrm{nm}$. Bottom, Same micrograph with color-coded vesicles. Filled circles represent stained vesicles. Red represents attached. Green represents docked at AZ. Blue represents around T-bar. Cyan represents internal. The T-bar is outlined for clarity. A larger proportion of stained vesicles around the T-bar (filled blue vs filled cyan). C, The proportion of recycled vesicles within different groups after 10 min passive loading. A lower proportion of internal (cyan) stained vesicles compared with the attached (red) and docked at AZ (green) vesicles. Data collected from 14 AZs (2 larvae). D, The proportion of recycled vesicles at different groups after 2 min passive loading. A very low proportion of stained attached vesicles (red). Data collected from $12 \mathrm{AZs}$ ( 2 larvae). $\boldsymbol{E}$, The proportion of recycled vesicles at different groups after $30 \mathrm{~s}$ passive loading. The highest proportion of stained vesicles occurs around T-bar (blue). Data collected from 12 AZs (2 larvae). 

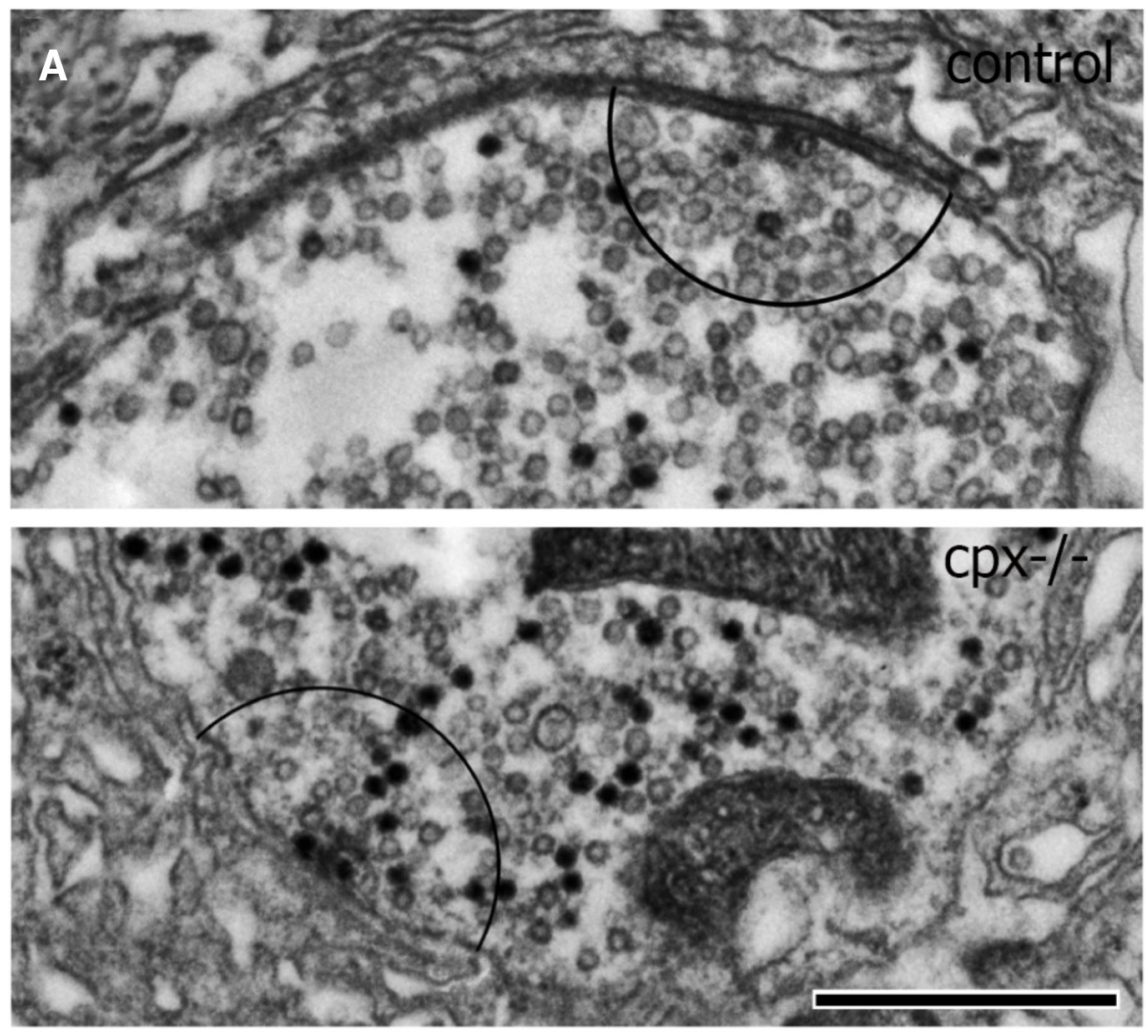

B

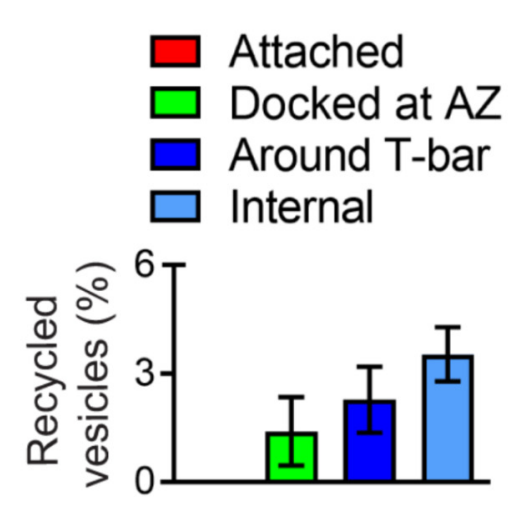

C

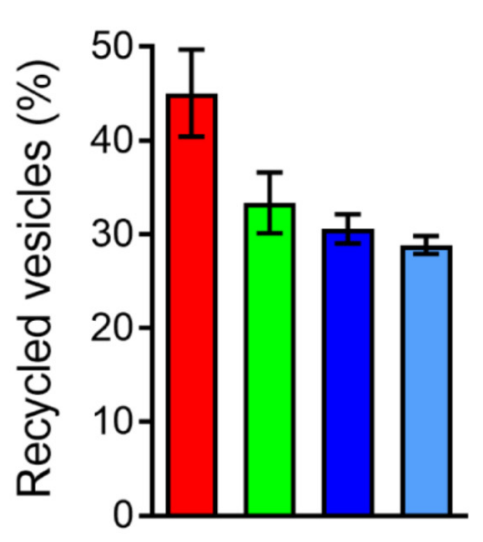

D
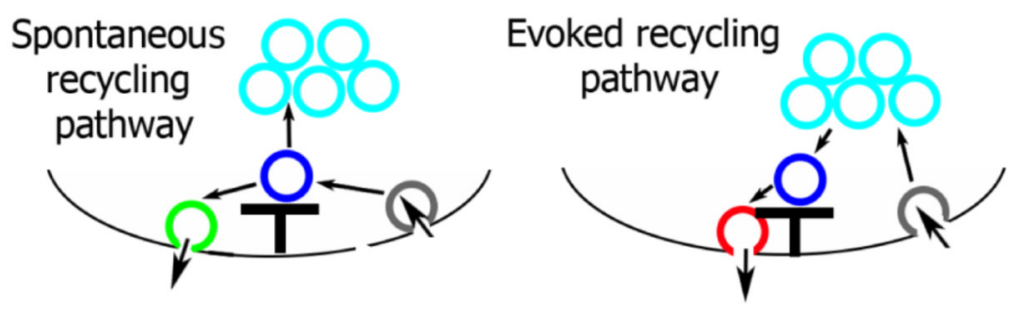

Figure 8. The spatial organization of vesicles recycled during the nerve stimulation is altered in $c p x^{-1-}$ boutons. Preparations were stimulated at $5 \mathrm{~Hz}$ for $5 \mathrm{~min}$. $A$, Representative micrograph showing recycled vesicles at WT and $\mathrm{cpx}^{-1-}$ boutons after active dye loading. Stained (black) vesicles are uniformly distributed over the entire $\mathrm{cpx}^{-/-}$bouton, whereas in the WT bouton most of the stained vesicles are not in the vicinity of the T-bar (the area outlined by a black semicircle, at a radius of $300 \mathrm{~nm}$ around the T-bar). Scale bar, $500 \mathrm{~nm}$. $\boldsymbol{B}$, In WT preparations, recycled vesicles predominantly belong to the internal group (cyan bar). Data collected from 12 AZs (2 larvae). $C$, In $c p x^{-1-}$ boutons, recycled vesicles are distributed evenly and include those attached and docked at AZs, as well as internal. Data collected from 27 AZs (2 larvae). D, A model for evoked (1) and spontaneous (2) recycling pathways.
First, we investigated the recycling pathway that drives spontaneous fusion by analyzing the spatial distribution of vesicles stained after passive dye loading at $c p x^{-1-}$ boutons (Fig. $7 B, C$; 10 min loading). Interestingly, we found that $\sim 50 \%$ of docked vesicles were stained (green and red bars) and that the proportion of stained docked vesicles significantly exceeded the proportion of stained internal vesicles $(\sim 20 \%)$. This result suggests that spontaneous vesicle retrieval is likely to take place in the vicinity of T-bars, as shown in Figure $7 A 1, A 2$. It should be noted, however, that the $10 \mathrm{~min}$ dye loading paradigm (Fig. $7 B, C$ ) would allow considerable vesicle intermixing. Therefore, we analyzed the spatial distribution of stained vesicles produced with shorter loading times (Fig. $7 D, E$ ). We found that the shortest loading time used ( $30 \mathrm{~s}$; Fig. $7 E$ ) produced a preferential staining of the vesicles around T-bars (Fig. 7E, blue bar), but none of the stained vesicles belonged to the attached group (Fig. 7E, absent red bar). This result suggests that the "kiss and run" release and retrieval mode is unlikely. A longer loading time (2 min; Fig. $7 D$ ) produced a very small proportion of attached stained vesicles (2\%, red bar), and a larger proportion of stained vesicles docked at AZs (8\%, green bar), with the largest proportion of stained vesicles around the T-bar (13\%, blue bar). This overall retrieval pattern is most consistent with the recycling pathway presented in Figure $7 A 2$ where vesicles become retrieved in the vicinity of AZs and subsequently dock to the plasma membrane, with some of the recycled vesicles being directed toward the internal pool.

We next examined whether a similar scenario would occur with the evoked recycling pathway. To address this question, we analyzed the distribution of recycled vesicles (Fig. $8 \mathrm{~A}$ ) for preparations loaded with dye during nerve stimulation $(5 \mathrm{~Hz}$ for $5 \mathrm{~min}$ ). Because WT preparations show very low spontaneous release rates ( $<1$ vesicle per second per bouton) (Bykhovskaia et al., 2013), the staining pattern at stimulated evoked WT preparations largely reflects the evoked recycling pathway. In contrast, the staining pattern at stimulated $c p x^{-1-}$ preparations would reflect the simultaneous activity of evoked and spontaneous recycling. We found that in WT preparations the highest proportion of recycled vesicles were in the internal pool (Fig. 8B, cyan bar). No recycled vesicles were found in the attached group in WT boutons (Fig. 8B, absent red bar, $C$ ). This staining pattern 
matches the recycling pathway presented in Figure $7 A 3$ where retrieved vesicles are taken up into the internal pool and subsequently mobilized to AZs.

These results suggest that spontaneous and evoked release triggers different retrieval pathways, with spontaneous vesicle retrieval taking place at AZs (Fig. 7A2) and evoked retrieval involving the intraterminal pool (Fig. 7A3). If this is the case, then we could expect that the retrieval at stimulated $c p x^{-1-}$ preparations would represent a mixture of the two patterns because $c p x^{-1-}$ preparations have prominent evoked and spontaneous release components. Indeed, stimulated $c p x^{-1-}$ preparations had approximately half of the attached vesicles being stained (Fig. $8 C$, red bar), similar to the staining pattern observed during passive dye loading (Fig. 7C). In addition, these preparations also had a relatively large proportion of stained internal vesicles $(\sim 30 \%$; Fig. $8 C$, cyan bar). This result is consistent with partial segregation of vesicle recycling that is specific to the mode of release: vesicles preferentially recycle around AZs following spontaneous fusion, whereas evoked recycling involves the intraterminal vesicle pool (Fig. 8D).

\section{Discussion}

We took advantage of Drosophila $c p x^{-1-}$ mutant synapses to examine mechanisms of synaptic vesicle recycling. The loss of $c p x$ selectively promotes spontaneous exocytosis, providing an advantageous system to investigate how the endocytic machinery responds to accommodate the enhanced spontaneous exocytosis. The spontaneous exocytosis rate in $c p x^{-1-}$ is increased 50- to 100-fold (Bykhovskaia et al., 2013), and this increase is independent of external $\mathrm{Ca}^{2+}$ (Jorquera et al., 2012). We found that synaptic boutons can accommodate this drastic increase in the spontaneous release without any noticeable vesicle depletion. These results show that endocytic rates in $c p x^{-1-}$ boutons adjust to accommodate the increased exocytic load, in agreement with earlier studies suggesting that the exocytic load largely determines the endocytic rate (Fernández-Alfonso and Ryan, 2006; Balaji and Ryan, 2007). It is still debated how the adjustment in endocytic rates occurs (Leitz and Kavalali, 2016). Only a subpopulation of all vesicles in the terminal, the recycling vesicle pool (Rizzoli and Betz, 2005), participates in the exocytic/endocytic process, and thus the size of the recycling pool may increase to accommodate the increased exocytic load. Conversely, the endocytosis process may be accelerated without any increase in the recycling pool. Our results suggest that increased spontaneous release is accommodated by an increase in the recycling vesicle pool.

One could argue that Cpx deletion may enhance endocytic rates directly. However, three lines of evidence suggest that that this is not the case. First, we observed that the recycling pool at rest is increased in another mutant with enhanced spontaneous exocytosis, the paralytic syntaxin mutant $s y x^{3-69}$. Second, we did not detect any alterations in the architecture of active and periactive zones in $c p x^{-1-}$ boutons using EM and immunocytochemistry, even though we cannot rule out entirely a potential role for altered levels or localization of some components of the endocytosis pathway. Third, we found that $\mathrm{Ca}^{2+}$ levels in $c p x^{-1-}$ boutons are not altered. These data argue that the increased recycling pool in $c p x^{-1-}$ boutons is produced by compensatory vesicle retrieval triggered by enhanced exocytosis, and suggest that $c p x^{-1-}$ boutons can be used as a genetic model to study the recycling pathway associated with spontaneous activity. If this is the case, then the conclusions obtained for the $c p x^{-I-}$ mutant can be generalized, suggesting that spontaneous fusion followed by retrieval represents a separate recycling pathway that uses a specialized vesicle pool. Although further studies are needed to unambiguously establish the $c p x^{-1-}$ mutant as a model to study spontaneous recycling pathway at normal synapses, the results obtained in a different mutant line, $s y x^{3-69}$, support the relationship between enhanced rates of spontaneous fusion and an increase in the recycling vesicle pool used at rest.

Our results also suggest that the spontaneous recycling pool created in $c p x$ boutons only partially intermixes with the recycling pool available for evoked transmission. Indeed, our FM1-43 loading experiments demonstrated that activating the evoked recycling pathway adds to the spontaneous recycling pool. Furthermore, FM1-43 destaining experiments suggested that spontaneous exocytosis primarily involves the spontaneous recycling pool. However, our results also suggest that the evoked recycling pool can participate in spontaneous exocytosis, but with slower kinetics. In line with this interpretation, the analysis of synaptic depression in the presence of the vesicle refilling blocker Baf indicates that the vesicle pool available for evoked transmission can be partially depleted by spontaneous release, but to a lesser extent than the vesicle pool available for spontaneous transmission.

These results elucidate the question of whether evoked and spontaneous vesicle turnover is separated. Although it has been long debated (Voglmaier and Edwards, 2007) whether evoked and spontaneous synaptic transmission originates from the same vesicle population, recent evidence suggests these two pathways have certain molecular (Crawford and Kavalali, 2015) and morphological (Melom et al., 2013) distinctions. On the other hand, several studies (Groemer and Klingauf, 2007; Hua et al., 2010; Wilhelm et al., 2010) provide strong evidence that spontaneous and recycling vesicle pools can intermix. Our results suggest that the spontaneous and evoked endocytic pathways produce additive recycling pools, which can partially intermix during exocytosis.

Our findings also suggest that the spontaneous vesicle turnover largely involves vesicles surrounding AZs, but not those attached to $\mathrm{Ca}^{2+}$ channels directly under the T-bar. Two lines of evidence support this model. First, $c p x^{-1-}$ boutons showed a selective depletion of vesicles around T-bars and those docked at AZs, but not the docked vesicles attached to T-bars. This result suggests that spontaneous exocytosis largely involves vesicles, docked at a distance from $\mathrm{Ca}^{2+}$ channels, that are clustered nearby to T-bars (Owald and Sigrist, 2009). Second, FM1-43 loading coupled with photoconversion and EM analysis at distinct time points demonstrated that spontaneously recycled vesicles in $c p x^{-1-}$ boutons are initially found predominantly around T-bars and subsequently become docked or directed inside the terminal. Notably, a different distribution was observed for the evoked recycling pool, suggesting a model (Fig. $7 D$ ) where retrieved vesicles become intermixed with intraterminal vesicles and subsequently become docked at $\mathrm{Ca}^{2+}$ channels and undergo fusion.

In conclusion, the detailed analysis of synaptic vesicle recycling in $c p x^{-1-}$ boutons allowed us to delineate endocytic/exocytic pathways for spontaneous and evoked release components. It has been long recognized that vesicle reuptake can occur in different modes, which may depend on the experimental preparation and the stimulation paradigm (Saheki and De Camilli, 2012; Wu et al., 2014). It has been documented that vesicles can be retrieved at periactive zones via clathrin-mediated endocytosis. Intense stimulation paradigms can also induce bulk membrane reuptake followed by vesicle pinching off. Finally, in certain experimental conditions, vesicles can be fused and re- 
trieved at AZs without losing their identity. It has been long debated how these endocytic mechanisms contribute to recycling pathways during different experimental conditions. Our study suggests that transient vesicle fusion and reuptake are unlikely to be a prevalent recycling mechanism for either evoked or spontaneous release at the Drosophila NMJ. In addition, these findings suggest that spontaneous and evoked release components mobilize separate recycling pathways (Fig. $8 D$ ) that form separate recycling pools. However, these recycling pools partially intermix during exocytosis, possibly as they undergo a sorting process in the vicinity of AZs.

\section{References}

Akbergenova Y, Bykhovskaia M (2007) Synapsin maintains the reserve vesicle pool and spatial segregation of the recycling pool in Drosophila presynaptic boutons. Brain Res 1178:52-64. CrossRef Medline

Akbergenova Y, Bykhovskaia M (2009a) Enhancement of the endosomal endocytic pathway increases quantal size. Mol Cell Neurosci 40:199-206. CrossRef Medline

Akbergenova Y, Bykhovskaia M (2009b) Stimulation-induced formation of the reserve pool of vesicles in Drosophila motor boutons. J Neurophysiol 101:2423-2433. CrossRef Medline

Akbergenova Y, Bykhovskaia M (2010) Synapsin regulates vesicle organization and activity-dependent recycling at Drosophila motor boutons. Neuroscience 170:441-452. CrossRef Medline

Aravanis AM, Pyle JL, Tsien RW (2003) Single synaptic vesicles fusing transiently and successively without loss of identity. Nature 423:643-647. CrossRef Medline

Balaji J, Ryan TA (2007) Single-vesicle imaging reveals that synaptic vesicle exocytosis and endocytosis are coupled by a single stochastic mode. Proc Natl Acad Sci U S A 104:20576-20581. CrossRef Medline

Bykhovskaia M, Jagota A, Gonzalez A, Vasin A, Littleton JT (2013) Interaction of the complexin accessory helix with the C-terminus of the SNARE complex: molecular-dynamics model of the fusion clamp. Biophys J 105: 679-690. CrossRef Medline

Cho RW, Song Y, Littleton JT (2010) Comparative analysis of Drosophila and mammalian complexins as fusion clamps and facilitators of neurotransmitter release. Mol Cell Neurosci 45:389-397. CrossRef Medline

Cho RW, Kümmel D, Li F, Baguley SW, Coleman J, Rothman JE, Littleton JT (2014) Genetic analysis of the Complexin trans-clamping model for cross-linking SNARE complexes in vivo. Proc Natl Acad Sci U S A 111: 10317-10322. CrossRef Medline

Choi BJ, Imlach WL, Jiao W, Wolfram V, Wu Y, Grbic M, Cela C, Baines RA, Nitabach MN, McCabe BD (2014) Miniature neurotransmission regulates Drosophila synaptic structural maturation. Neuron 82:618-634. CrossRef Medline

Cochilla AJ, Angleson JK, Betz WJ (1999) Monitoring secretory membrane with FM1-43 fluorescence. Annu Rev Neurosci 22:1-10. CrossRef Medline

Cork KM, Van Hook MJ, Thoreson WB (2016) Mechanisms, pools, and sites of spontaneous vesicle release at synapses of rod and cone photoreceptors. Eur J Neurosci 44:2015-2027. CrossRef Medline

Cousin MA, Nicholls DG (1997) Synaptic vesicle recycling in cultured cerebellar granule cells: role of vesicular acidification and refilling. J Neurochem 69:1927-1935. CrossRef Medline

Cousin MA, Robinson PJ (2000) $\mathrm{Ca}(2+)$ influx inhibits dynamin and arrests synaptic vesicle endocytosis at the active zone. J Neurosci 20:949957. Medline

Crawford DC, Kavalali ET (2015) Molecular underpinnings of synaptic vesicle pool heterogeneity. Traffic 16:338-364. CrossRef Medline

Fernández-Alfonso T, Ryan TA (2006) The efficiency of the synaptic vesicle cycle at central nervous system synapses. Trends Cell Biol 16:413-420. CrossRef Medline

Groemer TW, Klingauf J (2007) Synaptic vesicles recycling spontaneously and during activity belong to the same vesicle pool. Nat Neurosci 10:145147. CrossRef Medline

Hallermann S, Silver RA (2013) Sustaining rapid vesicular release at active zones: potential roles for vesicle tethering. Trends Neurosci 36:185-194. CrossRef Medline

Hallermann S, Kittel RJ, Wichmann C, Weyhersmüller A, Fouquet W, Mertel S, Owald D, Eimer S, Depner H, Schwärzel M, Sigrist SJ, Heckmann M
(2010) Naked dense bodies provoke depression. J Neurosci 30:1434014345. CrossRef Medline

Harata NC, Aravanis AM, Tsien RW (2006) Kiss-and-run and full-collapse fusion as modes of exo-endocytosis in neurosecretion. J Neurochem 97: 1546-1570. CrossRef Medline

Harata N, Ryan TA, Smith SJ, Buchanan J, Tsien RW (2001) Visualizing recycling synaptic vesicles in hippocampal neurons by FM $1-43$ photoconversion. Proc Natl Acad Sci U S A 98:12748-12753. CrossRef Medline

He L, Wu LG (2007) The debate on the kiss-and-run fusion at synapses. Trends Neurosci 30:447-455. CrossRef Medline

Hua Y, Sinha R, Martineau M, Kahms M, Klingauf J (2010) A common origin of synaptic vesicles undergoing evoked and spontaneous fusion. Nat Neurosci 13:1451-1453. CrossRef Medline

Huntwork S, Littleton JT (2007) A complexin fusion clamp regulates spontaneous neurotransmitter release and synaptic growth. Nat Neurosci 10: 1235-1237. CrossRef Medline

Imig C, Min SW, Krinner S, Arancillo M, Rosenmund C, Südhof TC, Rhee J, Brose N, Cooper BH (2014) The morphological and molecular nature of synaptic vesicle priming at presynaptic active zones. Neuron 84:416-431. CrossRef Medline

Jiao W, Masich S, Franzén O, Shupliakov O (2010) Two pools of vesicles associated with the presynaptic cytosolic projection in Drosophila neuromuscular junctions. J Struct Biol 172:389-394. CrossRef Medline

Jorquera RA, Huntwork-Rodriguez S, Akbergenova Y, Cho RW, Littleton JT (2012) Complexin controls spontaneous and evoked neurotransmitter release by regulating the timing and properties of synaptotagmin activity. J Neurosci 32:18234-18245. CrossRef Medline

Karunanithi S, Georgiou J, Charlton MP, Atwood HL (1997) Imaging of calcium in Drosophila larval motor nerve terminals. J Neurophysiol 78: 3465-3467. Medline

Kavalali ET (2015) The mechanisms and functions of spontaneous neurotransmitter release. Nat Rev Neurosci 16:5-16. CrossRef Medline

Kavalali ET, Chung C, Khvotchev M, Leitz J, Nosyreva E, Raingo J, Ramirez DM (2011) Spontaneous neurotransmission: an independent pathway for neuronal signaling? Physiology (Bethesda) 26:45-53. CrossRef Medline

Klingauf J, Kavalali ET, Tsien RW (1998) Kinetics and regulation of fast endocytosis at hippocampal synapses. Nature 394:581-585. CrossRef Medline

Lagow RD, Bao H, Cohen EN, Daniels RW, Zuzek A, Williams WH, Macleod GT, Sutton RB, Zhang B (2007) Modification of a hydrophobic layer by a point mutation in syntaxin $1 \mathrm{~A}$ regulates the rate of synaptic vesicle fusion. PLoS Biol 5:e72. CrossRef Medline

Leitz J, Kavalali ET (2016) $\mathrm{Ca}^{2+}$ dependence of synaptic vesicle endocytosis. Neuroscientist 22:464-476. CrossRef Medline

Littleton JT, Chapman ER, Kreber R, Garment MB, Carlson SD, Ganetzky B (1998) Temperature-sensitive paralytic mutations demonstrate that synaptic exocytosis requires SNARE complex assembly and disassembly. Neuron 21:401-413. CrossRef Medline

Martin JA, Hu Z, Fenz KM, Fernandez J, Dittman JS (2011) Complexin has opposite effects on two modes of synaptic vesicle fusion. Curr Biol 21:97105. CrossRef Medline

Melom JE, Akbergenova Y, Gavornik JP, Littleton JT (2013) Spontaneous and evoked release are independently regulated at individual active zones. J Neurosci 33:17253-17263. CrossRef Medline

Murphy SM, Matthew SE, Rodgers HF, Lituri DT, Gibbins IL (1998) Synaptic organisation of neuropeptide-containing preganglionic boutons in lumbar sympathetic ganglia of guinea pigs. J Comp Neurol 398:551-567. CrossRef Medline

Owald D, Sigrist SJ (2009) Assembling the presynaptic active zone. Curr Opin Neurobiol 19:311-318. CrossRef Medline

Peng A, Rotman Z, Deng PY, Klyachko VA (2012) Differential motion dynamics of synaptic vesicles undergoing spontaneous and activity-evoked endocytosis. Neuron 73:1108-1115. CrossRef Medline

Ramirez DM, Kavalali ET (2011) Differential regulation of spontaneous and evoked neurotransmitter release at central synapses. Curr Opin Neurobiol 21:275-282. CrossRef Medline

Reese AL, Kavalali ET (2015) Spontaneous neurotransmission signals through store-driven $\mathrm{Ca}(2+)$ transients to maintain synaptic homeostasis. Elife 4.

Reim K, Mansour M, Varoqueaux F, McMahon HT, Südhof TC, Brose N, Rosenmund C (2001) Complexins regulate a late step in $\mathrm{Ca}^{2+}$. dependent neurotransmitter release. Cell 104:71-81. CrossRef Medline Richmond JE, Broadie KS (2002) The synaptic vesicle cycle: exocytosis and 
endocytosis in Drosophila and C. elegans. Curr Opin Neurobiol 12:499507. CrossRef Medline

Rizzoli SO (2014) Synaptic vesicle recycling: steps and principles. EMBO J 33:788-822. CrossRef Medline

Rizzoli SO, Betz WJ (2004) The structural organization of the readily releasable pool of synaptic vesicles. Science 303:2037-2039. CrossRef Medline

Rizzoli SO, Betz WJ (2005) Synaptic vesicle pools. Nat Rev Neurosci 6:5769. CrossRef Medline

Rodal AA, Motola-Barnes RN, Littleton JT (2008) Nervous wreck and Cdc42 cooperate to regulate endocytic actin assembly during synaptic growth. J Neurosci 28:8316-8325. CrossRef Medline

Ryan TA (2001) Presynaptic imaging techniques. Curr Opin Neurobiol 11: 544-549. CrossRef Medline

Saheki Y, De Camilli P (2012) Synaptic vesicle endocytosis. Cold Spring Harb Perspect Biol 4:a005645. CrossRef Medline

Sara Y, Virmani T, Deák F, Liu X, Kavalali ET (2005) An isolated pool of vesicles recycles at rest and drives spontaneous neurotransmission. Neuron 45:563-573. CrossRef Medline

Schikorski T, Stevens CF (2001) Morphological correlates of functionally defined synaptic vesicle populations. Nat Neurosci 4:391-395. CrossRef Medline

Schneggenburger R, Rosenmund C (2015) Molecular mechanisms governing $\mathrm{Ca}(2+)$ regulation of evoked and spontaneous release. Nat Neurosci 18:935-941. CrossRef Medline

Smith SM, Renden R, von Gersdorff H (2008) Synaptic vesicle endocytosis: fast and slow modes of membrane retrieval. Trends Neurosci 31:559-568. CrossRef Medline

Stevens RJ, Akbergenova Y, Jorquera RA, Littleton JT (2012) Abnormal synaptic vesicle biogenesis in Drosophila synaptogyrin mutants. J Neurosci 32:18054-18067. CrossRef Medline

Südhof TC (2013a) A molecular machine for neurotransmitter release: synaptotagmin and beyond. Nat Med 19:1227-1231. CrossRef Medline

Südhof TC (2013b) Neurotransmitter release: the last millisecond in the life of a synaptic vesicle. Neuron 80:675-690. CrossRef Medline

Voglmaier SM, Edwards RH (2007) Do different endocytic pathways make different synaptic vesicles? Curr Opin Neurobiol 17:374-380. CrossRef Medline

Watanabe S, Liu Q, Davis MW, Hollopeter G, Thomas N, Jorgensen NB, Jorgensen EM (2013a) Ultrafast endocytosis at Caenorhabditis elegans neuromuscular junctions. Elife 2:e00723. CrossRef Medline
Watanabe S, Rost BR, Camacho-Pérez M, Davis MW, Söhl-Kielczynski B, Rosenmund C, Jorgensen EM (2013b) Ultrafast endocytosis at mouse hippocampal synapses. Nature 504:242-247. CrossRef Medline

Wilhelm BG, Groemer TW, Rizzoli SO (2010) The same synaptic vesicles drive active and spontaneous release. Nat Neurosci 13:1454-1456. CrossRef Medline

Wragg RT, Snead D, Dong Y, Ramlall TF, Menon I, Bai J, Eliezer D, Dittman JS (2013) Synaptic vesicles position complexin to block spontaneous fusion. Neuron 77:323-334. CrossRef Medline

Wu LG, Betz WJ (1996) Nerve activity but not intracellular calcium determines the time course of endocytosis at the frog neuromuscular junction. Neuron 17:769-779. CrossRef Medline

Wu LG, Hamid E, Shin W, Chiang HC (2014) Exocytosis and endocytosis: modes, functions, and coupling mechanisms. Annu Rev Physiol 76:301331. CrossRef Medline

Xue M, Craig TK, Xu J, Chao HT, Rizo J, Rosenmund C (2010) Binding of the complexin $\mathrm{N}$ terminus to the SNARE complex potentiates synapticvesicle fusogenicity. Nat Struct Mol Biol 17:568-575. CrossRef Medline

Xue M, Reim K, Chen X, Chao HT, Deng H, Rizo J, Brose N, Rosenmund C (2007) Distinct domains of complexin I differentially regulate neurotransmitter release. Nat Struct Mol Biol 14:949-958. CrossRef Medline

Xue M, Stradomska A, Chen H, Brose N, Zhang W, Rosenmund C, Reim K (2008) Complexins facilitate neurotransmitter release at excitatory and inhibitory synapses in mammalian central nervous system. Proc Natl Acad Sci U S A 105:7875-7880. CrossRef Medline

Xue M, Lin YQ, Pan H, Reim K, Deng H, Bellen HJ, Rosenmund C (2009) Tilting the balance between facilitatory and inhibitory functions of mammalian and Drosophila Complexins orchestrates synaptic vesicle exocytosis. Neuron 64:367-380. CrossRef Medline

Yang X, Kaeser-Woo YJ, Pang ZP, Xu W, Südhof TC (2010) Complexin clamps asynchronous release by blocking a secondary $\mathrm{Ca}^{2+}$ sensor via its accessory alpha helix. Neuron 68:907-920. CrossRef Medline

Yang X, Cao P, Südhof TC (2013) Deconstructing complexin function in activating and clamping $\mathrm{Ca}^{2+}$-triggered exocytosis by comparing knockout and knockdown phenotypes. Proc Natl Acad Sci U S A 110:2077720782. CrossRef Medline

Zhai RG, Bellen HJ (2004) The architecture of the active zone in the presynaptic nerve terminal. Physiology (Bethesda) 19:262-270. CrossRef Medline 